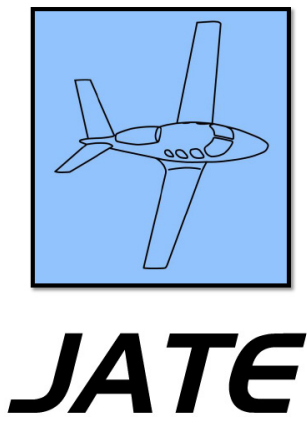

Journal of Aviation Technology and Engineering 4:2 (2015) 2-19

\title{
A Contribution Toward Better Understanding of Overbanking Tendency in Fixed-Wing Aircraft
}

\author{
Nihad E. Daidzic
}

AAR Aerospace Consulting, LLC

\begin{abstract}
The phenomenon of overbanking tendency for a rigid-body, fixed-wing aircraft is investigated. Overbanking tendency is defined as a spontaneous, unbalanced rolling moment that keeps increasing an airplane's bank angle in steep turns and must be arrested by opposite aileron action. As stated by the Federal Aviation Administration, the overbanking tendency may lead to a loss of control, especially in instrument meteorological conditions. It was found in this study that the speed differential over wing halves in horizontal turns indeed creates a rolling moment that achieves maximum values for bank angles between 45 and 55 degrees. However, this induced rolling moment may already be a part of other lateral-directional stability derivatives, most probably in dihedral effect. Nevertheless, the overbanking tendency may also be induced by propulsive and/or gyroscopic moments, airplane and flight control rigging problems, human factors, and improper piloting techniques. Straightforward explanation of the overbanking tendency is based on the asymptotic spiral divergence lateral-directional mode, which is very common in many FAR 23 airplane designs. The full nonlinear stability model, which may include coupling of longitudinal, lateral, and directional motion in steep turns at high angles of attack and including propulsive moments, may be required to make the final judgment about the existence of the overbanking tendency. A thorough review of airplane turning performance in horizontal plane is presented.
\end{abstract}

Keywords: aircraft stability and control, overbanking tendency, roll and yaw stiffness, roll and yaw damping, stability derivatives, steep turns aerodynamics and performance

\footnotetext{
About the Author

Nihad E. Daidzic is president of AAR Aerospace Consulting, L.L.C. He is also a tenured full professor of Aviation, adjunct professor of Mechanical Engineering, and research graduate faculty at Minnesota State University. His Ph.D. and Sc.D. are in fluid mechanics and mechanical engineering, respectively. He was formerly a staff scientist at the National Center for Microgravity Research and the National Center for Space Exploration and Research at NASA Glenn Research Center in Cleveland, $\mathrm{OH}$. He has also held various faculty appointments at Vanderbilt University, University of Kansas, and Kent State University. His current research interest is in theoretical, experimental, and computational fluid dynamics, micro- and nano-fluidics, aircraft stability, control, and performance, mechanics of flight, piloting techniques, and aerospace propulsion. Daidzic is a CFI/MEI/CFIG and an ATP with flight experience in airplanes, helicopters, and gliders. Correspondence concerning this article should be sent to aaraerospace@cs.com.
} 


\section{Introduction}

One of the common points of confusion and contention in the aviation community is the phenomenon called the overbanking tendency (OBT) in steep turns. The definition of OBT can be summarized as a spontaneous increase of bank angle in steep turns, which requires active attention and opposite aileron deployment to stop further bank increase. The study presented here is an attempt to explain the origin and the existence (or absence) of the OBT. To make the final conclusive statements, more research that ventures into the field of coupled longitudinal and lateraldirectional (L-D) nonlinear stability of fixed-wing aircraft incorporating destabilizing power/thrust effects, inertial and aerodynamic coupling, and so forth, is necessary. However, the question of OBT may be simply explained as human reaction where pilots see the overbanking tendency caused by whatever reason as threatening. Any underbanking tendency (UBT) is simply seen as an annoyance.

The Federal Aviation Administration (FAA, 2004) defines OBT in terms of the steep bank where the outside wing portion must complete the larger circle in the same time as the inner wing half. Thus there is speed difference which causes lift differential resulting in an unbalanced roll toward the inside of the turn. However, many other effects such as thrust, inertial, and aerodynamic moments that act on an airplane could also be responsible for OBT. The basic reasoning of the FAA is that the spontaneous OBT at steep bank angles could be dangerous and must be actively addressed by pilots.

It is understandable that the FAA (and other regulatory agencies that deal with certification of pilots) is concerned with the fact that OBT can cause in-flight loss-of-control (LOC-I). This is especially true in instrument meteorological conditions (IMC) due to pilot distractions and high workload. As a matter of fact, Langewiesche (1972) reports that it is common to assume that an inexperienced pilot left to himself/herself will most likely end a flight catastrophically in a spiral dive (i.e., "graveyard spiral") and crash (or cause airplane in-flight breakup). Simultaneously, several adverse human and aeromedical factors are associated with the high-g loading during steep-turning downward spiraling flight.

The FAA requires specific steep-turn performance flight training for private $\left(45^{\circ} \pm 5^{\circ}\right)$ and commercial $\left(50^{\circ} \pm 5^{\circ}\right)$ pilot candidates (FAA, 2002a; 2002b). Steep turns are to be practiced also with one of the stated goals to recognize and neutralize OBT. Superficial explanation of the OBT is provided in some FAA training materials (FAA, 2004, pp. 3-9, 9-1).

\section{Literature Review}

In the technical aerospace and aeronautics literature on airplane stability and control, there is absolutely no reference to OBT anywhere. The small-perturbation linear stability theory, which is a workhorse in airplane design, is based on the initial work of Professor G. H. Bryan in his 1911 book on stability in aviation. A nice summary of early airplane control and stability technology development is given by Perkins (1969). The author highlights many important stability phenomena and states that some of the early flight-tests in WWII airplanes have shown that oscillatory Dutch-roll (D-R) is important, but controlling the spiral divergence is not. In specialized and advanced books on airplane stability and control, such as Etkin (1959), Kolk (1961), Seckel (1964), Ashley (1992), Russell (1996), Abzug and Larrabee (1997), Nelson (1998), Hodgkinson (1999), Stevens and Lewis (2003), Stengl (2004), Etkin (2005), Roskam (2007), and Schmidt (2012) there is no mentioning of the OBT in any L-D stability context. There is also no specific discussion of roll stability in steep turns and high bank angles. The only exception to this is the discussion of the span speed distribution during horizontal turns by Phillips (2004). Although Phillips (2004) does not call it OBT, his description of the phenomenon clearly points to it. As it will be shown here later, the effect of wing speeddifferential can be neglected when the diameter of a turn is much larger than the airplane's wingspan. It is apparent that Phillips (2004) considers this speed differential outside of the stability context. Moreover, the certification guidelines and regulations do not require testing of the aircraft flight dynamics at steep bank angles. As Phillips (2004) points out further, fixed-wing aircraft with low wing-loading and large wingspan (such as gliders) must take into account this speed differential which in very steep turns may cause stall of the lower wing.

Etkin (2005, p. 298), in discussing the roll stiffness, specifically states that aerodynamic rolling moments are not bank angle dependent and that any effect of it $\left(C_{l_{\phi}}\right)$ is already included in the lateral stability coefficient $C_{l_{\beta}}$, which is directly dependent on the sideslip angle $(\beta)$. Similar arguments were repeated by Nelson (1998), Raymer (1999), and Philips (2004). McCormick (1995, p. 518) states that $C_{l_{\phi}}$ is always zero, and that at best an airplane exhibits neutral roll stability in regard to bank angle $(\phi)$. As a matter of fact, unlike angle of attack (AOA or $\alpha$ ) or sideslip angle $(\beta)$, bank angle $(\phi)$ generates no aerodynamic moments per se.

A literature review of peer-reviewed, archived technical journals on aircraft stability and control yielded no specific return on OBT. It must be admitted that the search was not very in-depth or exhaustive, but nevertheless, no connection to OBT, or similarly, to L-D stability in steep-turns, returned any meaningful results. There are literally thousands of articles dealing with aircraft stability plus many NASA technical reports, and it is possible that this problem was addressed somewhere, sometime. However, no technical article was found that deals with the problem of OBT. 
On the other hand, regulatory fixed-wing aircraft pilot training requires practice of steep turns. Thus, a strong argument is made for OBT. For example, in FAA training material (FAA, 2004; FAA, 2013a), OBT is mentioned several times and some physical explanations are given. Interestingly, the old CAA civil pilot training manual (Cram \& Brimm, 1940) does not mention OBT anywhere, although it includes a very decent description of steep turns and load factors. However, OBT, or anything related to it, was never mentioned. The great Wolfgang Langewiesche (1972, p. 133) was perhaps the first to introduce the concept of OBT. In his book Stick and Rudder, originally published in 1944, his explanation of OBT was basically in line with the understanding of divergent spiral (in)stability of that time. On the other hand, former Lockheed engineering test pilot, Sammy Mason (1982) does not mention OBT anywhere in his book, Stalls, Spins, and Safety.

The late test pilot, flight instructor, and aviation educator extraordinaire Bill Kershner, who also taught aerobatic flying and advanced spin recoveries to the author of this article many years ago, does not mention OBT in his books on advanced pilot-oriented aerodynamics and airplane performance (1994) or on basic aerobatics (1996). As a matter of fact, torque (left-turning tendency), which will cause reduction in the bank angle in right steep turns (about $60^{\circ}$ ), is specifically mentioned. This would be a case of UBT caused by powerplant torque. Although not explicitly mentioned, it would be expected that small OBT exists in left turns, but this may be completely suppressed by dihedral effect (roll stiffness). It is thus unlikely that powerplant torque would cause any significant change in lateral stability. Additionally, Kershner (1994) describes the reduction of dihedral effect due to destabilizing power (propeller slipstream) effects in sideslips. Another basic aerobatic book (Campbell \& Tempest, 1989) makes no mention of OBT in the section on steep turns and advanced maneuvering.

Other pilot-oriented books on aerodynamics that even superficially touch on the subject of stability and control rarely mention OBT. The book on practical aerodynamics for pilots by Hurt (1965), Aerodynamics for Naval Aviators, includes a non-calculus-based basic introduction on static and dynamic airplane stability. However, nowhere is the term OBT mentioned, either in relation to steep turns or in any other stability or performance context. Hubin (1992) also makes no reference to OBT when discussing airplane aerodynamics. Specifically, in the section on the aerodynamics of turn or in the chapter on airplane stability, trim, and control and when discussing rolling motion there is no hint of OBT. On the other hand, Denker (2001) is a big advocate of OBT, but his descriptions are commensurate with the ones used earlier and do not represent any new insights into OBT. Askue (2006) writes about flight testing of homebuilt airplanes and he discusses in simple terms all important L-D stability problems including spiral divergence and D-R modes. There is no discussion of OBT.
Anderson and Eberhardt (2001) make no mention of the OBT when discussing the physics of (steep) turns. Neither does Smith (1992) when discussing aerodynamics of turns (including steep ones). While Swatton (2008; 2011) provides a very decent introduction on airplane static and dynamic stability, OBT is not mentioned.

Since gliders (sailplanes) are also fixed-wing aircraft, some references were checked there as well. Piggot (2002) makes no mention of OBT. Likewise, neither does Stewart (2001) when discussing glider aerodynamics. However, Conway (1989) and the FAA (2013a) address OBT in glider flying identically to the way it was explained for powered airplane flight. By reading many other national and international sources, it seems that OBT almost exclusively originates in US published fixed-wing pilottraining materials.

There are, of course, many non-peer-reviewed articles and opinions in the pilot community about OBT. For the sake of argument, the article by Lohmann (2003) argues against OBT, claiming that it is insignificant in conventional GA light-planes. On the other hand, Garrison (2011) advocates for OBT along the same arguments of differential wing speeds during turning motion. Some authors dispute any possibility that OBT exists, while others adamantly support it.

Is it possible, however, that both sides of the aisle are correct? A simple explanation is that differential speed, lift, and corresponding rolling moment in turns does indeed exist, but that this effect is already included and hidden in some stability derivatives. Even if it is not, it can be neglected for great majority of conventional FAR 23 and FAR 25 airplanes.

So does OBT really exist? Is OBT just a well-understood consequence of the gentle spiral divergence possibly combined with the small wing lift differential and associated rolling moment in steep turns? The answer cannot be definitively given, as some effects besides wing speed differential could still possibly, but very unlikely, lead to OBT in light GA FAR 23 airplanes. One such effect, which is essentially an unintentional active boundary-layer-control in significant sideslips in turns, could come from propeller slipstream (i.e., propwash). However, propeller slipstream is completely absent in gliders/sailplanes; thus, it is very difficult to see how that argument alone supports OBT. Some nonlinear coupling of aerodynamic and inertial effects do exist that could cause induced rotations around other body axes, but that is mostly reserved for high-performance fighter airplanes. Possible cause of OBT could be coupled roll-spiral oscillatory mode. This curious mode, often referred to as lateral-phugoid, is the consequence of unusual combination of stability derivatives (Hodgkinson, 1999).

This article asserts only a contribution toward better understanding of OBT. No final claims to the origin of OBT are given, other than the most likely causes. This article is neither an exhaustive review of the airplane L-D stability and 
control (as that would be a monumental work about which many great books have already been written) nor the definitive answer to the origin of OBT if it indeed exists.

\section{Mathematical Model of Turning Flight}

An illustration of the airplane in a constant-altitude horizontal plane turning flight with associated forces is shown in Figure 1. Here, $b$ is the wingspan, $\Gamma$ is dihedral angle, and $\phi$ is the bank angle.

\section{Flight Mechanics of Turning Flight}

A rigid-body non-rotating flat-earth model of airplane turning performance in arbitrary plane (Vinh, 1993) using the topocentric coordinate system $\left(x_{f}, y_{f}, z_{f}\right)$ fixed to the earth surface ( $z_{f}$ axis positive upward) and inertial, for all practical purposes here, yields a set of six coupled ordinary differential equations (ODE) describing the motion of the airplane's center of gravity (CG).

$$
\begin{aligned}
& \frac{d x}{d t}=V \cos \gamma \cos \psi \quad \frac{d y}{d t}=V \cos \gamma \sin \psi \quad \frac{d z}{d t}=V \sin \gamma \\
& \frac{d V}{d t}=g\left[\frac{T}{W} \cos \varepsilon-\frac{D}{W}-\sin \gamma\right] \\
& \frac{d \gamma}{d t}=\frac{g}{V}\left[\left(\frac{L}{W}+\frac{T}{W} \sin \varepsilon\right) \cos \phi-\cos \gamma\right] \\
& \frac{d \psi}{d t}=\frac{g}{V}\left(\frac{L}{W}+\frac{T}{W} \sin \varepsilon\right) \frac{\sin \phi}{\cos \gamma}
\end{aligned}
$$

The body $\left(x_{b}, y_{b}, z_{b}\right)$ or longitudinal-lateral-vertical axes (for roll, pitch, and yaw rotations) are fixed to aircraft (origin in CG). The first three ODE define speeds and location of the aircraft's CG in relationship to fixed inertial frame of reference. This set of equations can be considerably simplified, assuming that the thrust vector is collinear with the velocity vector ( $\cos \varepsilon \approx 1, \sin \varepsilon \approx 0$ ), and that turning performance takes place in the horizontal plane only. Thus, for constant-rate turn $(\omega)$ at fixed altitude $(\gamma=0, d \gamma / d t=0, d z / d t=0)$, Equation 1, simplifies to:

$$
\begin{aligned}
& \frac{d x}{d t}=V \cos \psi \quad \frac{d y}{d t}=V \sin \psi \quad \frac{d z}{d t}=0 \\
& \frac{d V}{d t}=g\left(\frac{T}{W}-\frac{D}{W}\right) \quad 0=\frac{g}{V}\left[\left(\frac{L}{W} \cos \phi\right)-1\right] \\
& \frac{d \psi}{d t}=\omega=\frac{g}{V}\left(\frac{L}{W}\right) \sin \phi
\end{aligned}
$$

The wind vector could be easily incorporated in the three ODE defining translational motion in $3 \mathrm{D}$ space around a fixed inertial coordinate system. All aircraft rotations and moments are described using the right-hand-rule convention. The body roll and pitch rates are both zero $(\dot{\phi}=0, \dot{\theta}=0)$, and all that is remaining of body rotations is the yaw rate. If the problem is of constant-airspeed $(d V / d t=0)$, Equation 2 reduces to (Anderson, 1999; Asselin, 1997; Eshelby, 2000; Hale, 1984; Mair \& Birdsall, 1992; McCormick, 1995; Phillips, 2004; Raymer, 1999; Saarlas, 2007; Vinh, 1993):

$$
T=D \quad L \cos \phi=W \quad L \sin \phi=\frac{W}{g} V \omega
$$

From the second equation in system (Equation 3), the vertical load factor $n$ is defined as:

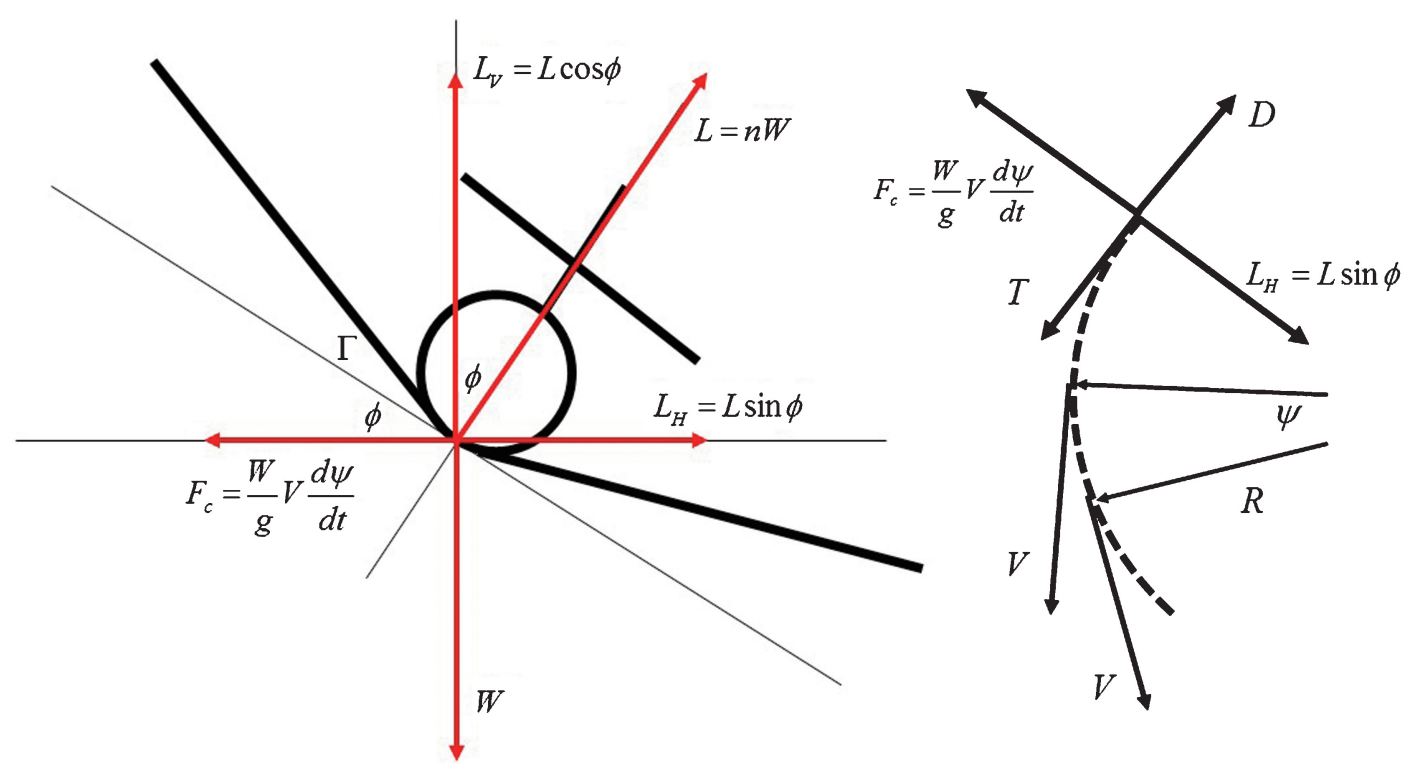

Figure 1. Aircraft in a constant-altitude turning flight in vertical (LHS) and horizontal (RHS) planes. Some geometry is highly exaggerated for better visual representation. 


$$
n=\frac{1}{\cos \phi}=\frac{L}{W}=\left(\frac{V}{V_{s}}\right)^{2} \quad \phi=\cos ^{-1}\left(n^{-1}\right)
$$

From the third equation in system (Equation 3), the angular velocity (change of heading $\psi$ ) of a turning aircraft or rate-of-turn (ROT) in a horizontal plane is given as:

$$
\mathrm{ROT}=\omega=\frac{d \psi}{d t}=\frac{g \tan \phi}{V}=\frac{g \sqrt{n^{2}-1}}{V}
$$

Here, $g$ is gravitational acceleration and the angular rotation velocity vector $\vec{\omega}$ in the fixed inertial reference system is perpendicular to the horizontal plane in which the turn takes place. The instantaneous radius-of-turn of the airplane's CG is:

$$
R=\frac{V}{\omega}=\frac{V^{2}}{g \tan \phi}=\frac{V^{2}}{g \sqrt{n^{2}-1}}
$$

Since an airplane is assumed to be a rigid-body and the angular speed is constant for all its body parts, the tangential speed will vary with the radius vector from the center of rotation. The centripetal force created by the horizontal lift component is the only active force causing the airplane to experience centripetal acceleration (change of direction). An opposing centrifugal force is generated as an apparent (inertial) force in non-inertial or accelerated frame of reference (airplane and its occupants).

Constant-altitude turning performance calculations are shown in Figure 2. Straight solid lines depict constant radius-of-turn $(\mathrm{R}=\mathrm{const})$ performance. The faster the airplane flies in a constant-radius constant-altitude turn, the higher the ROT, bank angle, and the n-load. The monotonously decreasing dashed curves depict constant vertical flight loads. A lift-limit (maximum coefficient-oflift) is represented by a solid curving line. For example, for an airplane with turning radius of $150 \mathrm{ft}$ (diameter of $300 \mathrm{ft})$ at $n=2.0 \quad\left(\phi=60^{\circ}\right)$, the stalling speed cannot exceed roughly 55 knots which corresponds to 38.9 knots stalling speed in level $n=1.0$ (1-g) flight. However, the same steep-turn with the bank angle of $60^{\circ}$ could be made at the radius of turn of $300 \mathrm{ft}$ (diameter of $600 \mathrm{ft}$ ) in which case the stalling speed in a turn cannot exceed 77 knots (1-g stalling speed of 54.5 knots). For example, a utilitycategory airplane designed for maximum vertical flight loads of $n=4.4\left(\phi=76.78^{\circ}\right)$ and $1-\mathrm{g}$ stalling speed of 50 knots (with corresponding maneuvering speed of 105 knots at MTOW) will have ROT of about 45 degrees/s and negotiate the horizontal (no-wind) circle with the radius of turn of about $230 \mathrm{ft}$ taking only about 8 s to complete a $360^{\circ}$ heading change (shown as red diamond marker in Figure 2). This is the cornering airspeed defining the maximum turning performance (largest ROT and shortest R) while limited by the maximum in-flight structural vertical load factor $\left(n_{\max }\right)$ and accelerated stalling speed (lift limit).

If this particular airplane is accelerated to, for example, 115 knots in a constant-altitude steep-turn, several options exist. Maintaining the same radius-of-turn (ROT increasing), the flight load and the bank angle will increase beyond the maximum design limit risking structural damage or failure. The second option is to hold constant ROT (about $45 \%$ shich would also lead to increased (albeit lesser) flight load and bank angles again violating the structural limits. However, there are no cockpit instruments that will

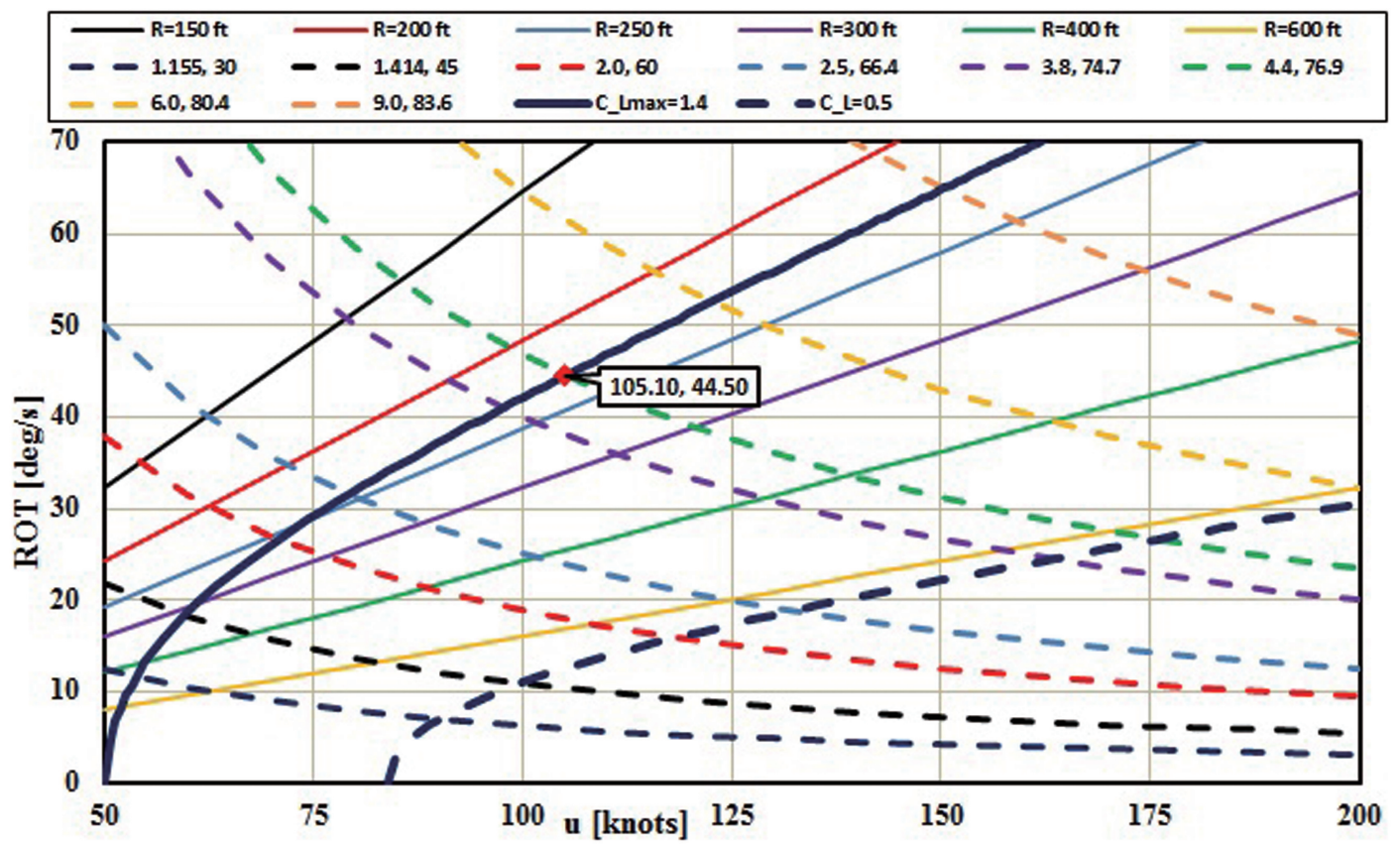

Figure 2. Airplane turning performance $\left(\mathrm{h}=\mathrm{SL}=\right.$ const., $\left.\mathrm{W} / \mathrm{S}=11.912 \mathrm{lb} / \mathrm{ft}^{2}, \mathrm{C}_{\mathrm{L}, \max }=1.4\right)$. 
show constant $\mathrm{R}$ or ROT. When increasing airspeed beyond maneuvering $\left(V_{A}\right)$, for example, from 105 to 115 knots, the maximum structural flight load $(n=4.4$ in this case) and the bank angle $\left(\phi=76.78^{\circ}\right)$ must be maintained, leading to lower ROT (about $42 \%$ ) and turning at larger R (about $260 \mathrm{ft}$ here). This could possibly be a dangerous scenario, as the airplane has the potential to create more lift and thus overstress its structure. However, the overwhelming majority of GA airplanes are thrust-/powerlimited to have such sustained super-maneuvering capability at maximum flight loads even when at lowest density altitudes (DAs). It takes an advanced aerobatic airplane or a maneuverable jet fighter to accomplish sustained high-performance turns. The stalling speed corresponds to the maximum coefficient-of-lift and is flight-load dependent.

\section{A Model of Differential Airspeed and Lift Generation in Turning Flight}

Due to velocity differential between the upper ("up") and the lower ("lw") wing halves, more lift will be produced on the elevated semi wing-span than on the lower one when the airplane is banked:

$$
\Delta L=L_{u p}-L_{l w}>0 \quad L_{\text {total }}=L_{u p}+L_{l w}
$$

The vertical component of the total lift must offset weight while the horizontal component provides for the centripetal force that causes the angular acceleration. In reality, the "adverse aileron" effect often exists, and depending on the airspeed, the first instantaneous reaction to aileron deployment may be the airplane's vertical climb or descent. Differential lift on wing halves in bank produces the rolling moment component:

$$
\widehat{L}_{\text {roll }}=\Delta L \cdot\left(\xi \frac{b}{4}\right) \quad \xi \leq 1
$$

The center of lift for each semi-span acts close to its respective center. The exact location will really depend on the lift distribution and the wing planform, requiring information on the sweep angle, taper ratio $\left(\lambda=c_{t} / c_{r}\right)$, chord change along the span, and other wing geometric characteristics. To simplify the problem, it is assumed here that the spanwise lift distribution is uniform. This is, of course, unrealistic, but acceptable approximation of spanwise lift distribution on a rectangular wing with unity taper ratio $(\lambda=1)$. The elliptical lift distribution is the one that produces minimum induced drag, uniform coefficient-oflift, and the spanwise lift distribution is, in fact, elliptical (Anderson, 1999; Asselin, 1997; Hurt, 1965; McCormick, 1995; Mair \& Birdsall, 1992; Nicolai \& Carichner, 2010; Phillips, 2004; Raymer, 1999; Saarlas, 2004; Vinh, 1993).

From the basic geometric considerations and assuming that half-wingspan lift acts in midpoints (Figure 1), the radius vectors for upper and lower radius-vectors which lay in different (non-horizontal) planes yield:

$$
\begin{aligned}
& R_{l w}^{2}=\left(R-\frac{b}{4} \cos \phi\right)^{2}+\left(\frac{b}{4}\right)^{2} \sin ^{2} \phi \\
& R_{u p}^{2}=\left(R+\frac{b}{4} \cos \phi\right)^{2}+\left(\frac{b}{4}\right)^{2} \sin ^{2} \phi
\end{aligned}
$$

The projection of the distance between the midpoints to horizontal plane where $\mathrm{CG}$ is located results in:

$$
\Delta s=R_{u p}-R_{l w} \approx \frac{b}{2} \cos \phi
$$

Differential tangential velocity between the midpoints separated by the wing semi-span is:

$$
\Delta V_{\omega=\text { const }}=V_{u p}-V_{l w}=\omega\left(R_{u p}-R_{l w}\right)=\frac{\omega b}{2} \cos \phi
$$

If constant-airspeed turns are made for bank angles not exceeding stalling conditions, one obtains:

$$
\begin{aligned}
& \Delta V_{u=c o n s t}=\frac{g b}{2 V} \sin \phi=\frac{V_{c s p}^{2}}{2 V} \sin \phi \\
& V_{c s p}=\sqrt{g b} \quad \phi_{\max } \leq \cos ^{-1}\left(n_{\max }^{-1}\right)
\end{aligned}
$$

The characteristic wingspan speed $V_{c s p}$ defines differential rotational motion of the wing with given span in the Earth's gravitational field. For a wingspan of 35 feet, the characteristic span speed differential is about 20 knots. If the airplane airspeed $(V)$ is held constant in a level-altitude turn, the speed differential changes as a sine function $(\sin \phi)$. This could lead to an erroneous conclusion that the speed differential is largest at $90^{\circ}$ bank angle. As a matter of fact, since the airspeed and altitude are kept constant, an arbitrary increase of bank angle will ultimately lead to stall first (Figure 2). Stalling speed will become infinite at $90^{\circ}$ bank "coordinated" constant-altitude turns. The differential wing speed for constant radius turns is:

$$
\begin{aligned}
& \Delta V_{R=\text { const }}=\frac{g b}{2 \sqrt{2 R g}} F_{R}(\phi)=\frac{\sqrt{2 R g}}{2}\left(\frac{b}{2 R}\right) F_{R}(\phi) \\
& F_{R}(\phi)=\sqrt{\sin 2 \phi}
\end{aligned}
$$

The constant turn-radius overbanking function $F_{R}(\phi)$ is shown in Figure 3. The variable $\sqrt{2 R g}$ is an "orbital" (circling) speed of turning airplane in a horizontal plane. For example, with a radius-of-turn of $300 \mathrm{ft}$, this circular speed is about 58 knots. The dimensionless ratio of wingspan and diameter of the turn is constant for given airplane and span-speed. The speed differential (Equation 13) increases up to bank angle of $45^{\circ}$ and then decreases to zero at $90^{\circ}$. Additionally, if the turn diameter is much larger than wingspan (as is usually the case) then wing speed differential is a very small value. If, on the other hand, the airspeed in a turn increases in a relationship to increasing 


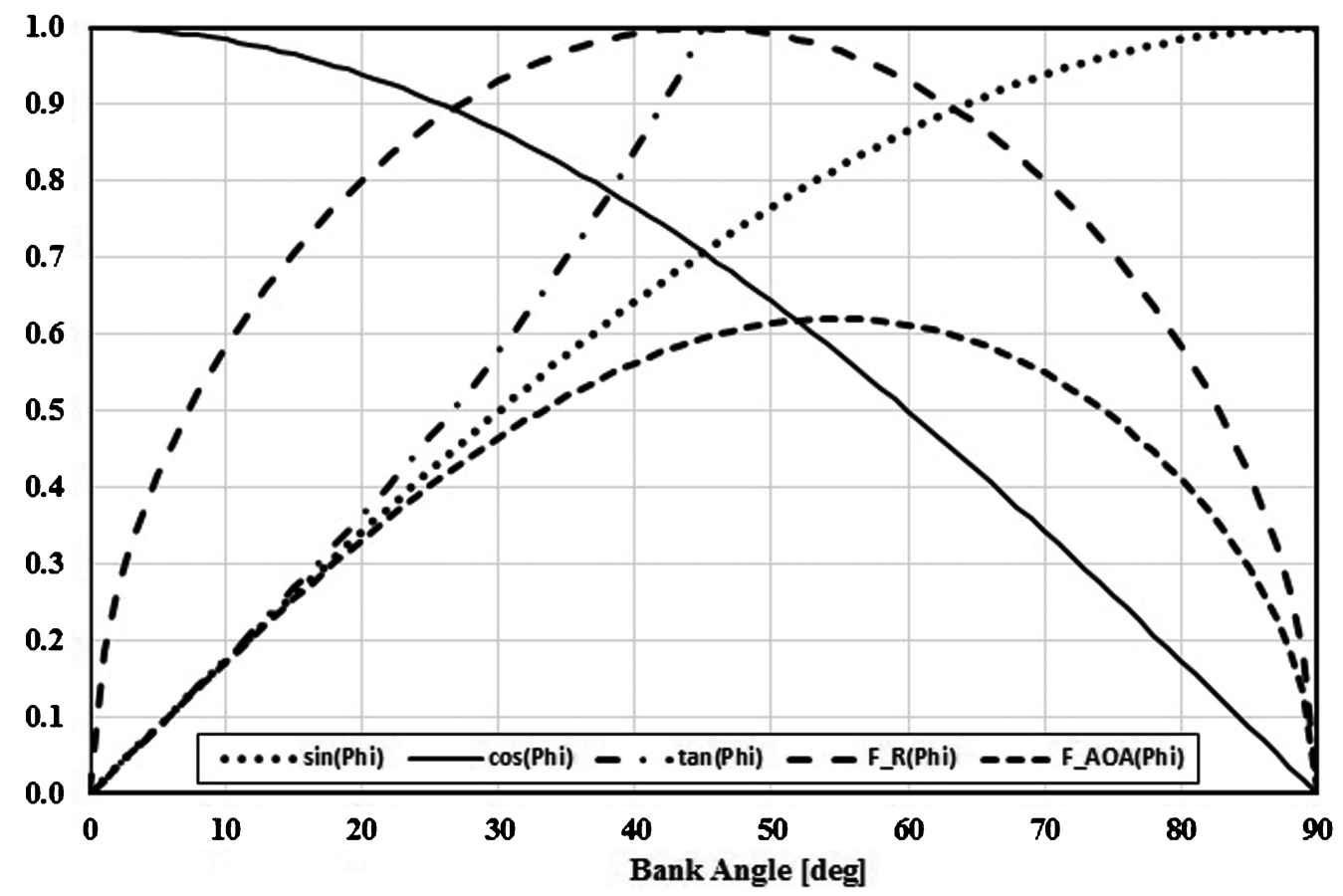

Figure 3. The plot of "overbanking functions" versus bank angle, $\phi$.

bank angle so that constant stall margin (constant AOA and $C_{L}$ ) is maintained, one obtains:

$$
V(k, \phi)=k V_{\text {so }} \sqrt{n}=\frac{k V_{\text {so }}}{\sqrt{\cos \phi}} \quad k=\text { const } \geq 1
$$

Here, $k$ is the constant factor of speed above the stall (e.g., $k=1.2$ ) and $k=1$ implies stall speed. By increasing the bank angle in a level-altitude turn, the wing-loading will increase and the airplane's stall margin will decrease at constant airspeed. This is how steep-turns are normally conducted. However, if $k$ is maintained constant by speeding up (this will need a lot of thrust) as the bank is increased, the speed differential between midpoints becomes:

$$
\Delta V_{C_{L}=\text { const }}=\frac{g b}{2 k V_{s o}} F_{A O A}(\phi)
$$

The highest speed differential is obtained in stalling turn $(k=1)$. The constant-AOA overbanking function $F_{A O A}(\phi)$ is also shown in Figure 3, and defined as:

$$
F_{A O A}(\phi)=\sin \phi \sqrt{\cos \phi}
$$

Thus, the constant-altitude steep-turns can be performed under various flight conditions:

1. Constant radius-of-turn $(R=$ const $)$

2. Constant rate-of-turn $(R O T=$ const $)$

3. Constant airspeed ( $V=$ const)

4. Constant $\operatorname{AOA}\left(C_{L}=\right.$ const $)$

Overbanking functions are different for various flight conditions listed above. Typically, steep-turns are made at constant airspeeds. However, if the airspeed stays constant while increasing the bank angle in constant-altitude turn, the AOA will increase and ultimately lift-limit will be reached. The wing lift differential for level-altitude steepturn becomes:

$$
\begin{aligned}
\Delta L(\phi) & =\frac{1}{2} \rho \frac{S}{2} C_{L}\left(V_{u p}^{2}-V_{l w}^{2}\right) \\
& =\frac{1}{2} \rho S C_{L} V_{C G} \Delta V=\frac{1}{2} \rho S C_{L} \frac{g b}{2} \sin \phi
\end{aligned}
$$

where $\Delta V=\left(V_{u p}-V_{l w}\right)$ and $2 V_{C G}=2 V=\left(V_{u p}+V_{l w}\right)$. Since static stability (tendency) is being explored from an equilibrium position (constant bank angle), one can assume approximately uniform $C_{L}$ on both wing halves. Utilizing Equation 8 with $\xi=1$, the rolling moment increment due to wing speed differential in a horizontal plane turn is:

$$
\Delta \widehat{L}_{\phi}(\phi)=\frac{1}{16} \rho b S C_{L}(g b) \sin \phi
$$

The rolling moment due to bank angle perturbation can be expressed as:

$$
\Delta \widehat{L}_{\phi}=C_{l}(\phi) \cdot Q \cdot S \cdot b=C_{l_{\phi}} \cdot \Delta \phi \cdot Q \cdot S \cdot b
$$

The aerodynamic rolling coefficient assuming constant coefficient-of-lift now becomes:

$$
\begin{aligned}
C_{l}(\phi) & =\frac{1}{8} \cdot\left(\frac{g b}{V^{2}}\right) \cdot C_{L}(\phi) \cdot \sin \phi \\
& =\frac{1}{4} \cdot\left(\frac{1}{\rho_{S L} \sigma}\right) \cdot\left(\frac{W}{S}\right) \cdot\left(\frac{g b}{V^{4}}\right) \cdot \tan \phi
\end{aligned}
$$


The non-dimensional bank angle dependent stability derivative (airspeed constant) yields:

$$
C_{l_{\phi}}=\frac{\partial C_{l}}{\partial \phi}=\frac{1}{4} \cdot\left(\frac{1}{\rho_{S L} \sigma}\right) \cdot\left(\frac{W}{S}\right) \cdot\left(\frac{g b}{V^{4}}\right) \cdot \frac{1}{\cos ^{2} \phi}>0
$$

For an airplane with a wingspan of $35 \mathrm{ft}$, wing loading of about $15 \mathrm{lb} / \mathrm{ft}^{2}$ flying 100 KCAS at SL, and the bank angle of $45^{\circ}$, one obtains $C_{l_{\phi}}=0.00437 \mathrm{rad}^{-1}$. For the same airplane turning at 75 knots (just above stall), the bank angle roll derivative becomes $C_{l_{\phi}}=0.01381 \mathrm{rad}^{-1}$. Induced rolling moment caused by a spontaneous increase of bank angle by $5^{\circ}$ at $45^{\circ}$ is $77 \mathrm{ft}-\mathrm{lb}$ at $100 \mathrm{KCAS}$ and $137 \mathrm{ft}-\mathrm{lb}$ at 75 knots respectively, which is very small indeed. To reiterate, Etkin (2005), McCormick (1994), and others deny any existence of $C_{l_{\phi}}$. The roll stiffness (effective dihedral) stability derivative is negative and usually around $C_{l_{\beta}}=-0.08$ for light GA FAR 23 airplanes (when not too close to the critical AOA).

\section{Methods and Materials}

A fictitious modern FAR 23-certified SEL GA utilitycategory airplane with constant-speed propeller, retractable-gear, and normally aspirated fuel-injected engine is used in this study. Technical data of the most important design parameters are given in Table 1.

\section{Thrust and Power Required in Constant-altitude Steep Turns}

Thrust and power required to meet sustained turning performance will be now described. The conventional subsonic drag polar for low Mach (M) numbers (Anderson, 1999; Asselin, 1997; Eshelby, 2000; Hale, 1984; Mair \& Birdsall, 1992; McCormick, 1994; Phillips, 2004; Raymer, 1999; Saarlas, 2007; Vinh, 1993) yields:

$$
\begin{aligned}
& C_{D}=C_{D, 0}+K \cdot C_{L}^{2} \quad \text { where }: \quad K \approx \frac{1}{\pi \cdot A R \cdot e} \\
& A R=\frac{b^{2}}{S}=\frac{b}{\bar{c}}
\end{aligned}
$$

Drag required in constant-airspeed level-altitude turn is:

$$
\begin{aligned}
T_{r} & =D(V, \sigma, n)=\frac{1}{2} \sigma \rho_{S L} V^{2} S C_{D} \\
& =\frac{\rho_{S L}}{2} \sigma S C_{D, 0} V^{2}+n^{2}\left(\frac{2 \cdot K \cdot S}{\sigma \cdot \rho_{S L}}\right)\left(\frac{W}{S}\right)_{n=1}^{2} \frac{1}{V^{2}}
\end{aligned}
$$

Clearly, thrust required for constant-airspeed, constantaltitude (steep) turns increases rapidly with the load factor (bank angle):

$$
\begin{aligned}
T_{a} & =\frac{\eta_{p}(V) \cdot B H P(\sigma)}{V}=T_{r}(V, \sigma, \phi) \\
& =\underbrace{\frac{\rho_{S L}}{2} \sigma S C_{D, 0} V^{2}}_{\text {Drag-not-due-to-Lift }}+ \\
& \underbrace{\left(\frac{1}{\cos ^{2} \phi}\right)\left(\frac{2 K S}{\sigma \rho_{S L}}\right)\left(\frac{W}{S}\right)_{n=1}^{2} \frac{1}{V^{2}}}_{\text {Drag-due-to-Lift }}
\end{aligned}
$$

Power of reciprocating engine (normally aspirated or turbo-charged/normalized) at given density altitude is, according to Asselin (1997):

$$
\begin{aligned}
& \frac{B H P_{a}(\sigma)}{B H P_{S L}}= \\
& \left\{\begin{array}{c}
1.0 \\
{\left[\frac{\sigma(h)}{\sigma_{\text {crit }}}\right]^{0.765}} \\
h_{\text {crit }} \leq h<h_{\text {ceiling }} \leq 36,151 \mathrm{ft}
\end{array}\right\}
\end{aligned}
$$

For constant-speed propellers, constant propulsive efficiency over range of airspeeds (typically $0.80-0.85$ ) is assumed. Thrust required increases in steepening turns exclusively because of the increase in drag-due-to-lift (which is predominantly due to increase in vortex- or induced-drag). It follows from Equation 23 that more thrust will be needed for airplanes with higher wing-loading, at higher altitudes, at slower airspeeds, and steeper bank angles. An example of thrust required and available turning performance as a function of airspeed and for various bank angles in constant altitude steep-turns for a typical GA airplane is shown in Figure 4. Power required for constantaltitude turning flight is:

$$
\begin{aligned}
T_{H} P_{a} & =\eta_{p}(V) \cdot B H P_{a}(\sigma)=T H P_{r}(V, \sigma, \phi) \\
& =\underbrace{\frac{\rho_{S L}}{2} \sigma S C_{D, 0} V^{3}}_{\text {Power-not-due-to-Lift }} \\
& +\underbrace{\left(\frac{1}{\cos ^{2} \phi}\right)\left(\frac{2 K S}{\sigma \rho_{S L}}\right)\left(\frac{W}{S}\right)_{n=1}^{2} \frac{1}{V}}_{\text {Power-due-to-Lift }}
\end{aligned}
$$

Minimum airspeeds in turns are limited by the stall (lift) limit $\left(C_{L, \max }\right)$ or thrust limits, while maximum are limited by the structural (maneuvering) loads. Corner airspeed is

Table 1

Essential performance parameters of fictitious FAR 23 utility-category GA airplane.

\begin{tabular}{ccccccccc}
\hline MTOW [lb] & $\mathrm{S}\left[\mathrm{ft}^{2}\right]$ & $\mathrm{b}[\mathrm{ft}]$ & $\mathrm{K}$ (cruise) & $C_{D, 0}$ (cruise) & $C_{L, \max }($ cruise) & MCP SL [HP] & $\eta_{p}[-]$ & $\mathrm{SFC}[\mathrm{lb} / \mathrm{hr} / \mathrm{BHP}]$ \\
\hline 2,600 & 170 & 35 & 0.0535 & 0.025 & 1.40 & 200 & 0.84 & 0.45 \\
\hline
\end{tabular}




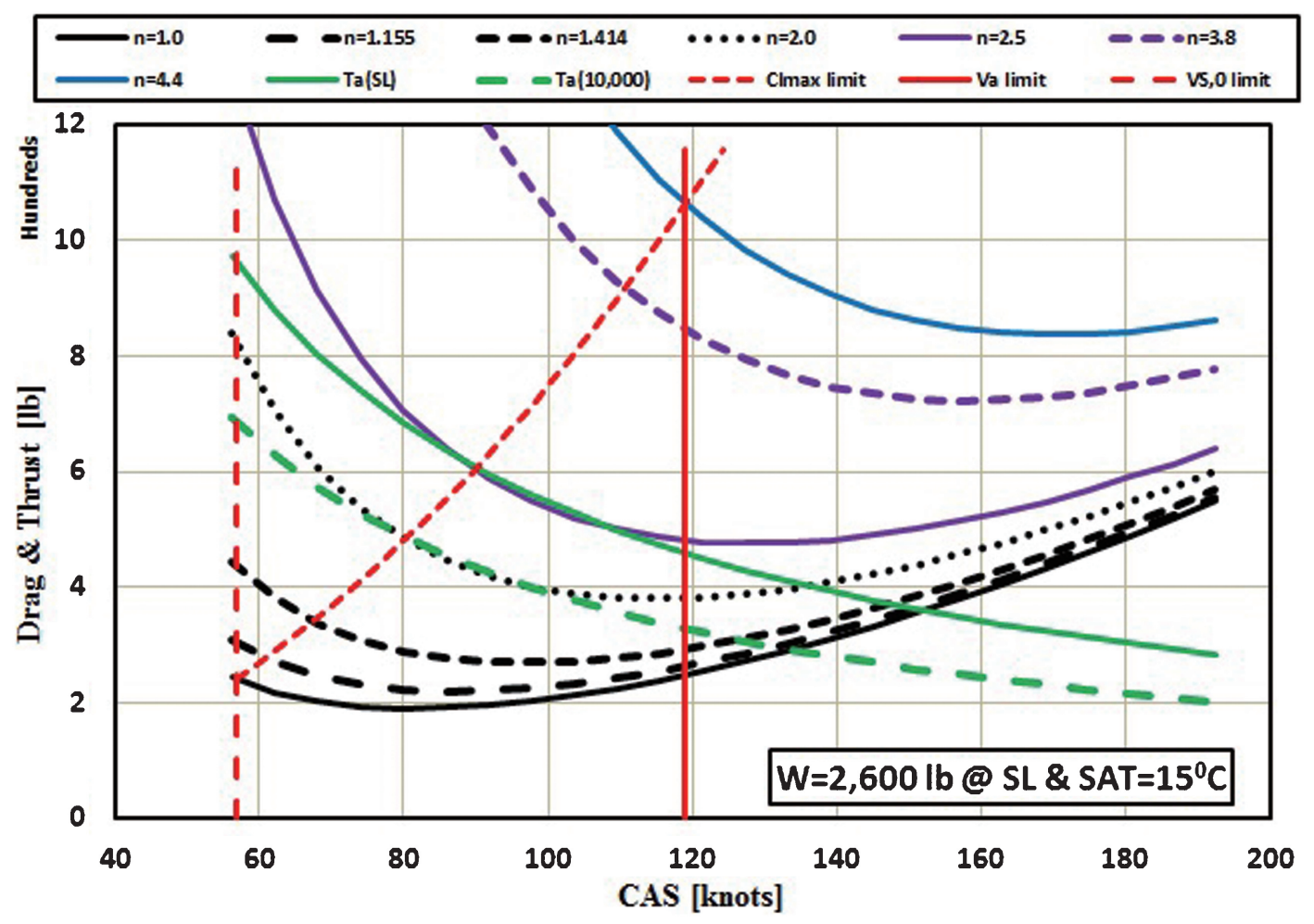

Figure 4. Thrust required in airplane turning performance.

attained at a point (corner) where structurally limited constant maneuvering airspeed intersects the maximum lift coefficient limit (here, $C_{L, \max }=1.4$ ) and is illustrated in Figure 2 with the red diamond marker. A normally aspirated fuel-injected reciprocating engine with the maximum continuous SL ISA power (MCP) of $200 \mathrm{HP}$ and the constant-speed propeller with efficiency of $84 \%$ assumed constant for the range of airspeeds discussed (from 50 to 150 knots) is used. Clearly, thrust from the reciprocating engine-propeller combination decreases with the true airspeed and altitude (not explicitly shown). Interestingly, the turn performance is thrust-limited $(600 \mathrm{lb})$ even at SL with the maximum sustaining load factor of $2.5\left(66^{\circ}\right)$ at $90 \mathrm{KCAS}$. At $10,000 \mathrm{ft} \mathrm{DA}$, the maximum sustained turn performance is at the load factor of $2.0\left(60^{\circ}\right)$ at $81 \mathrm{KCAS}$, requiring about $490 \mathrm{lb}$ of thrust. Thrust and power required to make sustained 4.4-g steepturn at about 119 knots at SL ISA conditions is almost $1,070 \mathrm{lb}$ and $400 \mathrm{HP}$, respectively. Thus, a significantly higher power-to-weight ratio is required to compensate for the significant induced drag increase incurred in sustained high-g load turning performance. It is much more likely to exceed structural limits by sudden (instantaneous) loading, such as in pulling out of the spiral dive and/or violent gusts. The power required curves as a function of load factor are shown in Figure 5. Vinh (1993) gives particularly detailed discussion of turning performance and calculation of various turn parameters. Unfortunately, he does not consider the effect of wing-speed differential in tight turns.
Static Lateral-Directional Stability of Fixed-Wing Aircraft

Airplane static stability in all three body axes requires that (Etkin, 2005; Nelson, 1998):

$$
C_{m_{\alpha}}<0 \quad C_{l_{\beta}}<0 \quad C_{n_{\beta}}>0
$$

These stability derivatives define pitch-stiffness (longitudinal stability), roll-stiffness (dihedral or lateral stability), and yaw-stiffness (weathercock or directional stability), respectively. It must be noted that these stability derivatives for the given geometry are predominantly functions of Mach number and AOA (Stevens \& Lewis, 2003), for example, $C_{l_{\beta}}=f(\alpha, M)$. Some essential L-D stability and control derivatives for a fictitious GA SEL retractable utility-category airplane certified under FAR 23 and in cruise configuration are summarized in Table 2. These are approximate values to show the relative importance. The mass moment of inertia for the rolling motion is, $I_{x x}=1,000$ slug- $\mathrm{ft}^{2}=1,356 \mathrm{~kg}-\mathrm{m}^{2}$, while the mass moment of inertia around the vertical axis is taken as $I_{z z}=3,500$ slug- $\mathrm{ft}^{2}=4,743 \mathrm{~kg}-\mathrm{m}^{2}$.

\section{Dynamic Lateral-Directional Stability of Fixed-Wing Aircraft}

Stick-fixed L-D stability using state-space (Nelson, 1998) or Laplace transforms (Roskam, 2007) results in characteristic equations defining eigenvalues for essential eigenmodes (eigenvectors). Stick-free stability problems 


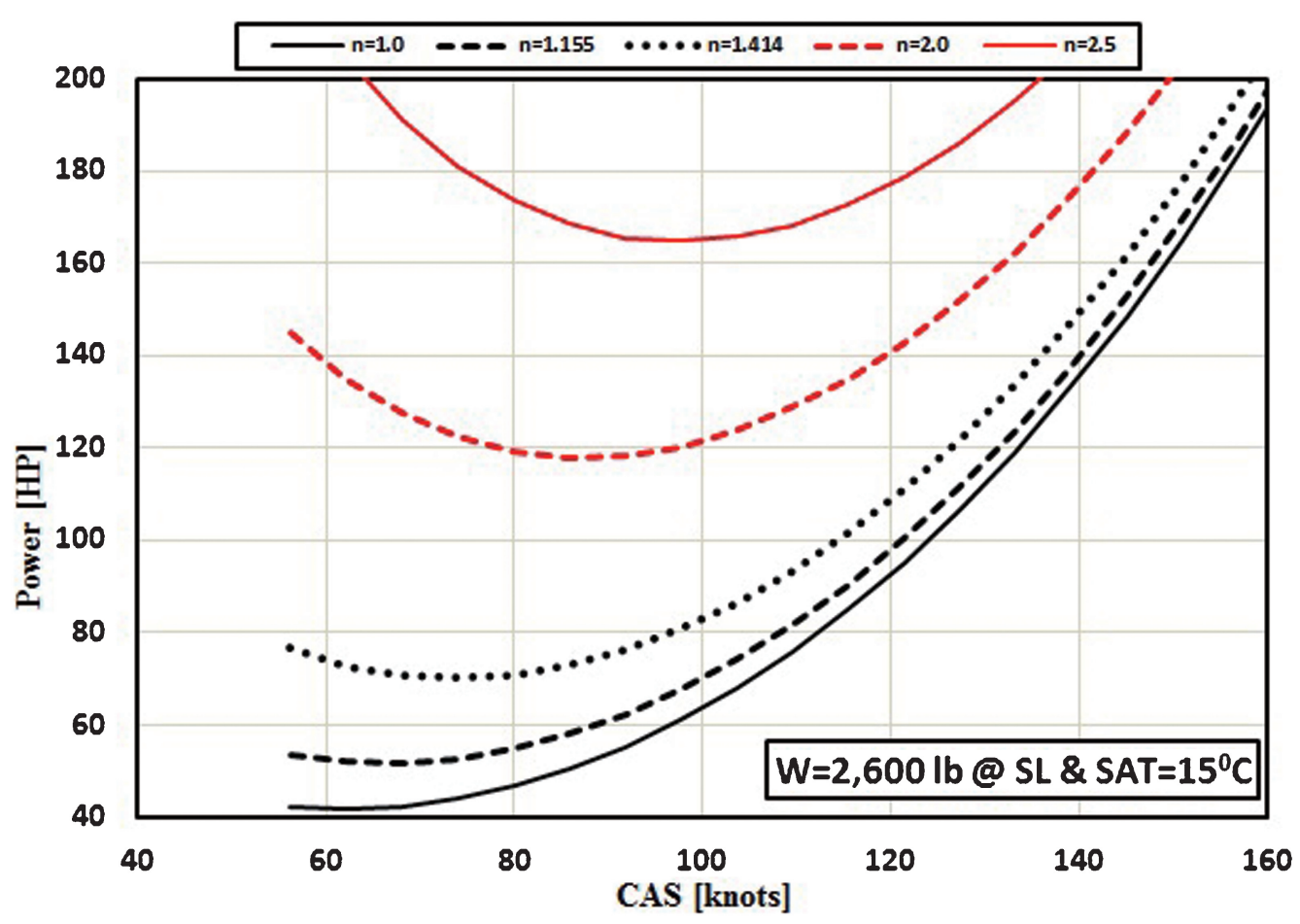

Figure 5. Power required in airplane turning performance.

are generally more complicated. The full coupled ODEs LD model is given in many references (e.g., Ashley, 1992; Etkin, 1959, 2005; Kolk, 1961; Nelson, 1998; Phillips, 2004; Roskam, 2007; Schmidt, 2012; Seckel, 1964; Stengl, 2004) and will not be repeated here due to lack of space. A quite general, factorized form of the linearized L-D 3-DOF (sideslip, roll, and yaw) flight dynamics results in:

$$
\begin{aligned}
& \lambda_{\psi} \cdot\left(\lambda-\lambda_{S}\right) \cdot\left(\lambda-\lambda_{R}\right) \cdot \\
& \left(\lambda_{D R}^{2}+2 \varsigma_{D R} \omega_{n, D R} \lambda_{D R}+\omega_{n, D R}^{2}\right)=0
\end{aligned}
$$

The lateral translational mode exhibits neutral stability with the single real root zero and is not shown here. Unlike in longitudinal stability where linearized equations can be applied to quite large disturbances, the L-D smalldisturbance linear stability theory can only be applied to truly small perturbations from the equilibrium points. Practically, every L-D mode with larger amplitudes will also involve coupling with longitudinal stability equations, making it a truly 6-DOF problem (Phillips, 2004). The most important variables in L-D stability are sideslip, roll, and yaw and their interactions. The aircraft is completely ignorant of a heading (yaw) angle in free flight and, once disturbed, has no natural tendency to return to it. This signifies neutral stability expressed through the real root, $\lambda_{\psi}=0$.

In the case of a simple real root, $\lambda=\lambda_{r}=\eta$, the disturbance may converge (decay) for $\eta<0$ or diverge (increase) for $\eta>0$ in an asymptotic, monotonic way according to exponential growth/decay, $\Delta=\Delta_{0} \exp (\eta t)$, with the time to double or halve the original disturbance $T_{2}$ or $T_{1 / 2}=\ln (2) /|\eta|$. In the case of complex conjugate roots (for D-R), the roots are $\lambda_{1,2}=\eta \pm j \omega$ with the same positive or negative stability damping requirements as shown above. In that case, the dynamic response will be oscillatory damped, neutral or divergent, depending on the real part of the complex root, with the frequency close to natural frequency $\omega$ (imaginary part of the complexconjugate root).

The linear stability theory based on small perturbation from the steady-state (Ashley, 1992; Etkin, 1959; Etkin, 2005; Kolk, 1961; Nelson, 1998; Phillips, 2004; Roskam, 2007; Russell, 1996; Schmidt, 2008; Seckel, 1964; Stengl, 2004; Stevens \& Lewis, 2003) can give some reasonable answers on the stick-fixed airplane's L-D stability. Essentially, the remaining four coupled linear ODE (plus

Table 2

Stability and control derivatives of fictitious FAR 23 utility-category GA airplane in cruise.

\begin{tabular}{cccccccccc}
\hline$C_{l_{\beta}}\left[\mathrm{rad}^{-1}\right]$ & $C_{l_{p}}\left[\mathrm{rad}^{-1}\right]$ & $C_{l_{r}}\left[\mathrm{rad}^{-1}\right]$ & $C_{n_{\beta}}\left[\mathrm{rad}^{-1}\right]$ & $C_{n_{r}}\left[\mathrm{rad}^{-1}\right]$ & $C_{n_{p}}\left[\mathrm{rad}^{-1}\right]$ & $C_{l_{\delta_{a}}}\left[\mathrm{rad}^{-1}\right]$ & $C_{l_{\delta_{r}}}\left[\mathrm{rad}^{-1}\right]$ & $C_{n_{\delta_{r}}}\left[\mathrm{rad}^{-1}\right]$ \\
\hline-0.090 & -0.480 & +0.080 & +0.060 & -0.100 & -0.030 & +0.140 & +0.015 & -0.060 \\
\hline
\end{tabular}


we could include some kinematic conditions) can be solved using the state-space analysis, resulting generally in four eigenvalues, of which two are real, and there is one complex-conjugate solution describing $\mathrm{D}-\mathrm{R}$ mode. The location of characteristic equation roots is made very convenient using the root-locus-technique developed by W.R. Evans in 1949. The basic lateral-directional stability modes are:

1. Spiral mode (asymptotic convergent or divergent)

a. Spiral divergence (divergent spiral mode)

b. Spiral convergence (convergent spiral mode)

2. Roll mode (asymptotic highly damped convergent)

3. Dutch-roll (oscillatory convergent or divergent)

The D-R mode $\lambda_{D R}$ is usually a low-frequency, oscillatory, lightly damped mode incorporating rolling, yawing, and sideslipping dynamics. Accordingly, the D-R mode is the complex-conjugate solution of the quadratic equation (in Equation 28) with the real part describing damping (positive, zero or negative) and the imaginary part corresponding to the D-R oscillation frequency. Simple analysis will show that D-R's yawing frequency, damping, and period are roughly (Kimberlin, 2003):

$$
\begin{aligned}
& \omega_{n, D R} \propto M \sqrt{\frac{p_{a} C_{n_{\beta}} S b}{I_{z z}}} \\
& \varsigma_{D R} \propto C_{n_{r}} \sqrt{\frac{\sigma S b^{3}}{I_{z z} C_{n_{\beta}}}} \quad T_{D R} \approx \frac{2 \pi}{\omega_{n, D R}}
\end{aligned}
$$

Increasing the yaw stiffness $\left(C_{n_{\beta}}\right)$ will reduce damping of D-R oscillations, but it will increase its frequency. Only by increasing yaw damping $\left(C_{n_{r}}\right)$ and/or flying at lower altitude $(\sigma)$ can D-R oscillations damping be increased for given aircraft geometry.

The spiral mode is asymptotic motion in roll and yaw with little sideslip. However, a true 6-DOF spiral divergence incorporates longitudinal changes with rolling into sideslip, turning, and descending into ever tighter spiral (i.e., "graveyard" or "death" spiral). The spiral divergence mode is often the preferable stability mode in light GA airplanes and is subconsciously corrected by pilots. The spiral divergence mode simply means that the directional stability is "stronger" than the lateral stability. The stable spiral mode represents converging spiral and implies insufficient directional stability (e.g., small vertical tail surfaces). However, too much lateral stability and stable spiral convergence can induce dangerous "heading divergence" in which an airplane keeps wings almost level in an ever increasing sideslip (lack of directional stability), resulting in the airplane flying sideways and ultimately leading to main wing stall, structural damage, or vertical tail stall. Additionally, a too stable spiral mode will significantly degrade the D-R characteristics, often making it quite annoying if not outright hazardous. Thus, too much lateral stability is actually avoided in airplane design. As a matter of fact, effective dihedral effect is often relaxed to the point of neutral stability to make maneuvering and handling crisper. The spiral divergence and the ever increasing bank and yaw angle to address the sideslip are examples that Langewiesche (1972) used in his explanation of OBT.

Airplanes often have a slightly positive, neutral, or slightly negative spiral mode leading to asymptotic (nonoscillatory) dynamics. In some respects, one may think of the spiral mode to be almost neutrally stable so that any sideslip (or sudden heading change) induced will remain unchanged unless the pilot corrects for it. While spiral divergence sounds dangerous, the time constant to double diverging roll amplitudes can be several tens of seconds and is easily corrected. Moreover, the spiral divergence improves D-R damping. The roll-mode $\lambda_{R}$ is essentially highly damped pure-rolling motion described herein later.

The most important L-D stability derivatives are summarized in Table 3 (Stevens \& Lewis, 2003). The sheer number of stability coefficients (some are omitted) hints to the complexity of the L-D dynamics even for a linear small-perturbation theoretical approach. A very good example of wind-tunnel measurements and determination of stability and control characteristics of a new FAR 23 airplane was given recently by Biber (2006).

\section{Spiral Lateral-Directional Mode}

The spiral mode depends on single real root in complex plane, which describes asymptotic (convergent, neutral, or divergent) behavior. Typically, spiral stability will be set, slightly positive, or slightly negative, that is, close to neutral stability. Stable spiral mode implies, relatively speaking, larger influence of the roll stability over yaw stability. Spiral approximation can be used to roughly describe dynamic stability in terms of the static and dynamic stability coefficients. Spiral approximation neglects some very important contributions (Phillips, 2004), but has been historically used to determine relative influence of important stability derivatives. The spiral approximation leads to a real root (Etkin, 1959, 2005; Nelson, 1998; Roskam, 2007; Schmidt, 2012):

$$
\begin{aligned}
\lambda_{S} & =\frac{\widehat{L}_{\beta} \widehat{N}_{r}-\widehat{L}_{r} \widehat{N}_{\beta}}{\widehat{L}_{\beta}}=\widehat{N}_{r}-\widehat{N}_{\beta}\left(\frac{\widehat{L}_{r}}{\widehat{L}_{\beta}}\right) \\
& =\frac{Q S b^{2}}{2 V_{0} I_{z z}}\left(C_{n_{r}}-C_{n_{\beta}} \frac{C_{l_{r}}}{C_{l_{\beta}}}\right) \quad \widehat{L}_{\beta}<0
\end{aligned}
$$

Since the dihedral stability derivative is always negative for conventional airplanes, the condition for spiral stability (convergent spiral) is:

$$
C_{l_{\beta}} \cdot C_{n_{r}}-C_{n_{\beta}} \cdot C_{l_{r}}>0
$$

Phillips (2004) does not recommend the use of Equation 30. However, despite the fact that some important stability 
Table 3

Lateral-directional derivatives and their importance.

$C_{l_{\beta}} \quad$ Dihedral derivative ( $<0$ for positive stiffness)

$C_{n_{\beta}} \quad$ Yaw stiffness ( $>0$ for positive stiffness)

$C_{l_{p}} \quad$ Roll damping ( $<0$ for roll damping)

$C_{n_{r}} \quad$ Yaw damping ( $<0$ for yaw damping)

$C_{n_{p}} \quad$ Yawing moment due to roll rate (usually $<0$ ) (cross-derivative)

$C_{l_{r}} \quad$ Rolling moment due to yaw rate (usually $>0$ ) (cross-derivative)

$C_{Y_{\beta}} \quad$ Sideforce due to sideslip

$C_{Y_{r}} \quad$ Sideforce due to yaw rate

$C_{Y_{p}} \quad$ Sideforce due to roll rate

derivatives are omitted and that the numerical result can be in error compared to full eigenvalue problem by as much as a factor of 10 , it is still an acceptable and simple approximation of the spiral mode. The alternative would be to address the full eigenvalue problem of four coupled ODE, which is not difficult, but is not elaborated here.

For the particular airplane used here, using Equation 30 with the values from the Table 2 leads to a numerical value of +0.0042 , signifying spiral stability. The spiral root (Equation 29) is then $\lambda_{S}=-0.1672$ (converging spiral), and the time to halve the disturbance amplitude is $T_{1 / 2}=4.15 \mathrm{~s}$ for an airplane flying at $75 \mathrm{KCAS}$ with a density altitude $(\sigma=0.8)$ of about $7,500 \mathrm{ft}$. The amount of stability (or instability) changes with airspeed, altitude, and so forth. Unfortunately, too much spiral stability may lead to unacceptable D-R mode and ultimately to largeamplitude (longitudinal-lateral-directional) "heading divergence". In fact, it is very common in GA airplane designs to have slight spiral instability (divergence) where the time to double the bank angle is long (several tens of seconds at least) and is easily corrected in flight. For this fictitious airplane, a simple increase in roll-due-to-yaw cross stability derivative (e.g., $C_{l_{r}}=0.2$ ) will result in a value of -0.003 , which signifies spiral divergence. The spiral root in that case is $\lambda_{s}=+0.1194$ (diverging spiral), and the time to double the disturbance amplitude is $T_{2}=5.81 \mathrm{~s}$. Solving the full eigenvalue problem to double the disturbance will be almost a whole order of magnitude, larger signifying gentle spiral divergence. A way to design certain stability behavior in airplane design is discussed in many stability and control engineering books (Nelson, 1998; Phillips; 2004; Raymer, 1999; Schmidt, 2012; Stengl, 2004).

Generally, larger vertical tail surfaces will increase both the yaw stiffness, $C_{n_{\beta}}$, and the yaw damping, $C_{n_{r}}$, but will also generate additional drag. Increasing yaw stiffness will reduce D-R damping, which is not good. As Nelson (1998) and Phillips (2004) have noted, the best way to simultaneously achieve spiral stability and good D-R damping is by increasing the yaw damping alone. Modern highperformance airplanes have smaller vertical stabilizing surfaces to reduce drag while utilizing yaw dampers (rate controllers) to rapidly detect and dampen any D-R oscillatory dynamics while exhibiting stable spiral mode. Stability augmentation systems (SAS) are becoming common today when no simple geometric (passive) design solutions alone would suffice to meet various conflicting stability, control, and performance requirements. Adding fixed strakes, dorsal, and ventral fins can only go so far in achieving desired aircraft stability and control characteristics.

\section{Roll Control}

The roll rate and the bank angle control in a GA airplane are typically accomplished using the conventional ailerons (differential and/or Frise type). Opposite aileron deployment creates differential lift, which produces rolling moment about the longitudinal axis. Ailerons control the rolling rate, but not the bank angle directly. FAR 23 regulates some roll control requirements (FAR 23.157), which dictate aileron design. Aileron "control power" is described by the aileron control derivative (Nelson, 1998; Roskam, 2007):

$$
\begin{aligned}
& C_{l_{\delta_{a}}}=\frac{\partial C_{l}}{\partial \delta_{a}}=\frac{2 C_{L_{\alpha_{w}}} \tau_{\delta_{a}}}{S b} \int_{y_{1}}^{y_{2}} c(y) y d y \\
& C_{L_{\alpha_{w}}}=\frac{\partial C_{L}}{\partial \alpha_{w}} \quad \tau_{\delta_{a}}=\frac{d \alpha_{w}}{d \delta_{a}}
\end{aligned}
$$

Rolling moment, which is positive in a clockwise direction as seen from the cockpit, is created by differential aileron deployment, and its magnitude is determined from the aileron roll control power $C_{l_{\delta_{a}}}$ and averaged displacement angle, $\delta_{a}=\left(\delta_{a}^{L}+\delta_{a}^{R}\right) / 2$ (Phillips, 2004):

$$
\Delta \widehat{L}_{\text {aileron }}=\left(\frac{\partial \widehat{L}}{\partial \delta_{a}}\right) \cdot \Delta \delta_{a}=C_{l_{\delta_{a}}} \cdot \Delta \delta_{a} \cdot Q \cdot S \cdot b
$$

Each degree of aileron deflection for the fictitious GA airplane used here (Tables 1 and 2) creates specific rolling moments of about $493 \mathrm{ft}-\mathrm{lb} / \mathrm{deg}$ and $277 \mathrm{ft}-\mathrm{lb} / \mathrm{deg}$ at speeds of $100 \mathrm{KCAS}$ and $75 \mathrm{KCAS}$ respectively if aileron control derivative of $0.14 \mathrm{rad}^{-1}$ is used.

\section{Roll Damping}

Any rolling motion (in pre-stall region) will be opposed by roll damping. The chief contributor to roll damping is the wing. Roll damping does not exist in static stability sense, but only during dynamic response. Horizontal and vertical tail surfaces (stabilizers) also contribute to roll damping, but to a lesser degree. In the pre-stall region, any rolling motion changes the main wing's AOA, which then causes an increase of lift on the down-going wing and a decrease of lift on the up-going wing. Such lift distribution creates (linear) resistance to rolling and is thus proportional to the roll rate. The best way to validate roll damping data for a specific aircraft model is to perform flight tests and scale model wind tunnel experiments at different speeds and 
configurations. A relatively simple theoretical approach for wing roll-damping contribution is given, among others, in Nelson (1998):

$$
C_{l_{p}}=\frac{\partial C_{l}}{\partial p}\left(\frac{2 V_{0}}{b}\right)=-\frac{4 C_{L_{\alpha_{w}}}}{S b^{2}} \int_{0}^{b / 2} c(y) y^{2} d y<0
$$

\section{Pure Roll Dynamics}

In stability and control theory, the pure rolling motion (1-DOF) of a rigid body airplane is described with the following ODE (Nelson, 1998):

$$
\begin{gathered}
\sum \text { Rolling Moments }=\sum_{i} \widehat{L}_{i}=I_{x x} \frac{d^{2} \phi}{d t^{2}}=I_{x x} \frac{d p}{d t} \\
p=\dot{\phi}
\end{gathered}
$$

The roll (speed) $p$ defines the bank angle change in time. Control rolling moments are the result of the aileron (and/or spoiler) deployment to induce rolling motion, which may be opposed by roll-damping moments. In the small-perturbation linear stability theory, the pure rolling dynamics yields:

$$
\left(\frac{\partial \widehat{L}}{\partial \delta_{a}}\right)_{p} \Delta \delta_{a}+\left(\frac{\partial \widehat{L}}{\partial p}\right)_{\delta_{a}} \Delta p=I_{x x} \Delta \ddot{\phi}=I_{x x} \Delta \dot{p}
$$

This ODE can be rearranged to obtain a first-order linear ODE with constant coefficients (LTI), which describes a firstorder (asymptotic) linear time-invariant dynamic system (Nelson, 1998):

$$
\tau_{R} \cdot \Delta \dot{p}+\Delta p=K \cdot \Delta \delta_{a}
$$

where,

$$
\begin{gathered}
\tau_{R}=-\frac{1}{\widehat{L}_{p}}=-\frac{I_{x x} \cdot\left(\frac{2 V_{0}}{b}\right)}{C_{l_{p}} Q S b} \quad K=-\frac{L_{\delta_{a}}}{L_{p}}=-\frac{C_{l_{\delta_{a}}}}{C_{l_{p}}}\left(\frac{2 V_{0}}{b}\right) \\
\widehat{L}_{p}=\frac{1}{I_{x x}}\left(\frac{\partial \widehat{L}}{\partial p}\right)_{\delta_{a}} \quad \widehat{L}_{\delta_{a}}=\frac{1}{I_{x x}}\left(\frac{\partial \widehat{L}}{\partial \delta_{a}}\right)_{p}
\end{gathered}
$$

Bank angle is controlled by varying the roll speed (aileron and/or spoiler deflection angle) and the duration of aileron/spoiler deployment. The magnitude of the roll rate will cause variable intensity coupling with the yaw rate. A simple asymptotic solution of Equation 36 for step change in aileron deflection with zero ICs yields:

$$
\begin{aligned}
& \Delta p(t)=\Delta \dot{\phi}(t)=\left(1-e^{-t / \tau_{R}}\right) \cdot K \cdot \Delta \delta_{a}=p_{s s}\left(1-e^{-t / \tau_{R}}\right) \\
& \vartheta=\frac{p_{s s} b}{2 V_{0}}=-\frac{C_{l_{a}}}{C_{l_{p}}} \Delta \delta_{a}
\end{aligned}
$$

Here, $p_{s s}$ stands for the steady-state roll, and $\vartheta$ is the helix roll angle (dimensionless steady-state roll). Required helix angle is used to design/size ailerons and roll control power. For step (Heaviside function) aileron input, roll history is given by Equation 37. The roll rate (acceleration) is then the time derivative of Equation 37, resulting in:

$$
\Delta \dot{p}(t)=\Delta \ddot{\phi}(t)=\frac{K \cdot \Delta \delta_{a}}{\tau_{R}} e^{-t / \tau_{R}}=\frac{p_{s s}}{\tau_{R}} e^{-t / \tau_{R}}
$$

The bank angle temporal history is the integral of the roll (Equation 37), yielding:

$$
\begin{aligned}
\Delta \phi(t) & =\int_{0}^{t} \Delta p(t) d t=K \cdot \Delta \delta_{a} \cdot\left(t-\tau_{R}+\tau_{R} e^{-t / \tau_{R}}\right) \\
& =p_{s s}\left[t-\tau_{R} \cdot\left(1-e^{-t / \tau_{R}}\right)\right]
\end{aligned}
$$

Transfer functions (TF) for the roll and bank angle response using the Laplace transforms are (Nelson, 1998; Roskam, 2007):

$$
\begin{gathered}
\frac{\Delta p(s)}{\Delta \delta_{a}(s)}=\frac{K}{\left(1+s \tau_{R}\right)} \quad \frac{\Delta \phi(s)}{\Delta \delta_{a}(s)}=\frac{K}{s\left(1+s \tau_{R}\right)} \\
s \Delta \phi(s)=\Delta p(s)
\end{gathered}
$$

Results of computations for roll acceleration, roll, and bank angle for the fictitious airplane with important design parameters given in Tables 1 and 2 are shown in Figure 6. To stop the steady roll, one has to neutralize ailerons and wait for the roll damping to decrease the roll to zero to establish the desired bank angle. In practice, it is often necessary to apply some opposite aileron to achieve more expeditiously desired bank angles. However, rigging problems and friction could lead to the situation where the control roll rate is not actually zero with ailerons apparently neutralized. In order to model deceleration of rolling motion, one can solve ODE similar to Equation 36 with the zero aileron deflection (homogeneous ODE). With the ICs designating initial steady roll rate $p_{0}$ at the moment ailerons are neutralized, the solution for the roll deceleration, decreasing roll, and bank angle become:

$$
\begin{aligned}
& \Delta \dot{p}(t)=-\frac{p_{0}}{\tau_{R}} e^{-t / \tau_{R}} \quad \Delta p(t)=p_{0} e^{-t / \tau_{R}} \\
& \Delta \phi(t)=p_{0} \tau_{R}\left(1-e^{-t / \tau_{R}}\right)
\end{aligned}
$$

After one roll time-constant $\tau_{R}$ elapsed, the remaining roll is $36.8 \%$ of the initial $\left(p_{0}\right)$. If in an airplane with the roll time-constant of $0.2 \mathrm{~s}$ and the steady roll rate of $25^{\circ}$ per second, the ailerons are suddenly neutralized at bank angle of $55^{\circ}$, the final bank angle will then asymptotically stabilize at $60^{\circ}\left(\delta \phi \approx p_{0} \tau_{R}=5^{\circ}\right)$ after about one second (five roll time-constants). Accordingly, a pilot needs to lead aileron neutralization in order to achieve correct bank angle 


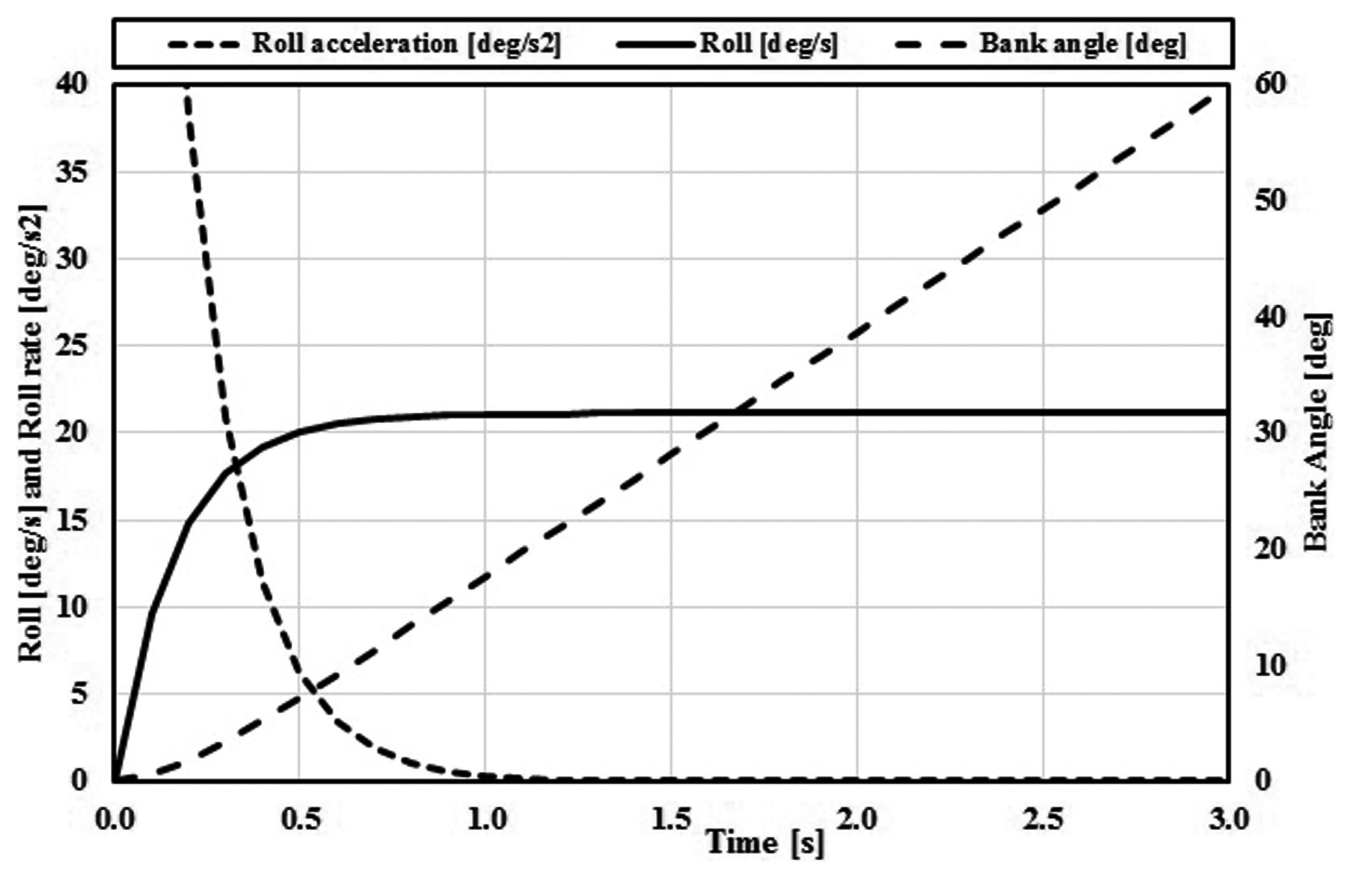

Figure 6. Roll control performance history with step aileron deflection.

asymptotically without overshooting and taking oppositeaileron corrective action.

For example, Grenestedt and Maroun (2006) were analyzing and flight testing simple canted tabs installed on trailing edges of ailerons to improve the stability of airplanes. Such canted tabs can be installed on almost any GA airplane to improve the stick-free L-D stability characteristics.

\section{Lateral-Directional Stability and Control Requirements for FAR 23 Airplanes}

Certification of normal, utility, aerobatic, and commuter category airplanes in the USA is conducted under 14 CFR Part 23 (FAA, 2013b). Equivalent regulations exist in EASA's CS 23 as well as in similar regulations in others' national aviation regulatory agencies. Interestingly, as a phenomenon, OBT is never mentioned in FAR 23. Generally, FAR 23.171 requires airplanes to have positive static stability. The L-D certification requirements in FAR 23.177 define conditions for the static lateral and directional stability. Similarly, FAR 23.181 spells out the requirements for longitudinal, lateral, and directional dynamic stability with controls free and fixed. Interestingly, only D-R mode is explicitly mentioned in FAR 23.181, and it is expected that roll mode is heavily damped while nothing is said on the spiral mode. There is no explicit requirement for spiral convergence. Consequently, the spiral divergence is not explicitly prohibited in FAR 23 . The flight test guide for FAR 23 airplanes is given in AC 23-8C (FAA, 2011) and covers many details not specifically mentioned in FAR 23. Military specifications in USA MIL-F-8785B/C allow for spiral divergence, but the time to double bank angle should not be less than 20 seconds. The flight testing method to establish compliance with MIL-F-8785B/C spiral-mode is deceptively simple-aircraft is banked with rudder only, which is then neutralized. The subsequent history of bank angle changes with time is recorded (Kimberlin, 2003).

Required roll performance for utility-category airplanes is covered in FAR 23.157 (FAA, 2013b). For example, FAR 23.157(a) requires roll control to change the bank from $30^{\circ}$ in one direction to $30^{\circ}$ in the other direction $\left(60^{\circ}\right.$ total) in less than 5 seconds for airplanes in takeoff configuration with MGTOW at or less than 6,000 lb. Similarly, FAR 23.157(c) sets roll performance requirements for airplanes in approach configuration weighing $6,000 \mathrm{lb}$ or less to roll airplane a total of $60^{\circ}$ from $30^{\circ}$ bank angle in one direction in less than four seconds. Approach configuration means landing gear is extended, flaps are in landing position, power is set for $3^{\circ}$ approach, and airspeed is at $\mathrm{V}_{\mathrm{REF}}$. Without going into detail, the directional control requirements are addressed in FARs 23.143, 23.147(b), 23.149, and 23.233 for different flight conditions.

Kimberlin (2003), Phillips (2004), and Roskam (2007) discuss certification requirements regarding L-D stability and control. Askue (2006) offers simple and practical flight testing guidelines for designers and builders of homebuilt aircraft. Askue also offers many practical advices on rigging and adjusting flight controls. In addition, he gives a very simple definition in testing of spiral mode: "The tendency to reduce bank is called spiral convergence and the tendency to increase bank angle is called spiral divergence" (Askue, 2006, p. 92). 
FAR 23 provides only the minimum standards for stability and control requirements. One of the first analytical approaches to aircraft flying or handling qualities were given by Kolk (1961), which was later also noted and praised by Ashley (1992). Many pilot rating scales have been developed to improve flying (handling) qualities. Among these, the Cooper-Harper scale (1969), consisting of 10 levels in four assessment groups, is the most popular (Hodgkinson, 1999; Kimberlin, 2003; Nelson, 1998; Roskam, 2007). However, the MIL-F-8785C (1980) simplifies the flying qualities ratings of the Cooper-Harper rating scale by summarizing them into only three levels of acceptable flying qualities (Kimberlin, 2003), which is in common use today. Since 1997, the flying qualities of piloted aircraft are evaluated according to MIL-HDBK1797, replacing the MIL-F-8785C (Nicolai \& Carichner, 2010). A more detailed review of aircraft handling qualities is given by Hodgkinson (1999). For example, Field et al. (2004) presented results of flight testing and model validation of large transport category airplanes (Boeing and MD) using frequency sweeps. Time histories of airplane responses were presented as frequency responses (gain and phase in Bode-type diagrams). Subsequent identification and application of flying qualities parameters can be then used for more accurate models and better design of flight control systems.

\section{Results and Discussion}

The overbanking functions discussed previously are all functions of the bank angle. The sine, cosine, and tangent functions are all familiar elementary trigonometric functions. The more exotic overbanking function $F_{A O A}(\phi)$ achieves the maximum when:

$$
\frac{d}{d \phi}\left[F_{A O A}(\phi)\right]=\frac{d}{d \phi}[\sin \phi \sqrt{\cos \phi}]=0 \quad 0 \leq \phi<90^{\circ}(42)
$$

The extremum condition from Equation 42 leads to the following transcendental equation, $\cos ^{2} \phi-\sin ^{2} \phi / 2=0$, with the solution $\phi_{o}=\sin ^{-1}( \pm \sqrt{2 / 3})=54.736^{\circ} \approx 55^{\circ}$, for which $F_{A O A}\left(\phi_{0}\right) \approx 0.62$ in the interval, $0 \leq \phi<90^{\circ}$. The constant-radius overbanking function reaches maximum when, $\phi_{0}=45^{\circ}$, in which case $F_{R}\left(\phi_{0}\right)=1.0$.

At $45^{\circ}$ bank angle, the airplane's CG airspeed of 100 knots and for SL altitude, the load factor is 1.4142 , the ROT $0.1905 \mathrm{rad} / \mathrm{s}$ (or $10.916 \%$ ), and the radius of turn is $886.4 \mathrm{ft}$. The speed differential between the upper and the lower wing midpoints is according to all four equations (Equations 12-15) 2.35 fps or 1.396 knots (i.e., 1.4 knots for all practical purposes or $1.4 \%$ of airplane's CG speed). Thus, the higher wing-half midpoint will experience airspeed of about 100.7 knots, the lower midpoint 99.3 knots, and the airplane's CG exactly 100 knots. For uniform coefficient-of-lift for both wing halves, the lift differential at a weight of 2,600 lb is only $51.35 \mathrm{lb}$. At 75 knots (level flight stall speed is 95.87 fps or 56.8 knots) and just 7 knots above the stalling speed and for the same bank angle and SL altitude, ROT is $0.254 \mathrm{rad} / \mathrm{s}$ or $14.55 \mathrm{deg} / \mathrm{s}$, the radius of turn is $498.6 \mathrm{ft}$ and the speed differential is 3.14 fps or 1.861 knots (2.48\% of airplane's airspeed). Hence, the rolling moment induced by banked wings definitely exists in horizontal turns, but it is also very small in most instances, with a few exceptions. The underlying reason for OBT may thus not be in the differential lift of a horizontally turning airplane, but in the built-in spiral divergence.

However, Etkin (2005, p. 300), Raymer (1999, p. 505), and McCormick (1995, p. 518), among many others, point out explicitly that the rolling moment cannot depend on the bank angle $\phi$. Bank angle by itself creates no aerodynamic moments and is fundamentally different than angle of attack and sideslip angles that govern longitudinal and L-D dynamics. Similarly, the yaw (heading) angle has no aerodynamic importance. Thus, turning-induced rolling motion due to wing speed-differential may be considered as a part of the rolling (dihedral) stiffness $C_{l_{\beta}}$ (Etkin, 2005) or of the cross derivative roll-due-to-yaw $C_{l_{r}}$, which are solely sideslip and yaw-rate dependent.

Chambers and Anglin (1969) discuss the L-D dynamics at high AOAs. Some phenomena associated with the high AOAs are also given in Hurt (1965). In the case of stall/ spin, the OBT is a natural airplane response where significant rolling, yawing, pitching, and sideslipping coexist. Mason (1982) and Kershner (1996) reported many interesting phenomena in spinning aircraft. Although Askue (2006) gives some recommendations on measuring the effective dihedral effect in medium banked turns, there is nothing in FAR 23 that requires testing aircraft L-D stability in turns (accelerated flight). Also, Kimberlin (2003) does not report on any such requirement or make such flight test recommendations. The small-perturbation linear stability theory cannot provide answers to all stability questions and one needs instrumented flight tests, windtunnel scale model testing, and simulation of the full nonlinear models that include all the coupling and energy transfers between various pure (normal) modes.

Interestingly, a rolling moment can be also triggered by pitching and yawing and when the difference between mass moments of inertia for vertical and lateral axes is not zero, which often is the case. Also, the product of inertia term coupled with the yaw acceleration and constant pitching and rolling rate induces roll moments (Abzug \& Larrabee, 1997). Gyroscopic forces from turning propellers may also become important in specific scenarios (pitching induces yawing, which induces rolling).

A factor that may lead to "pilot-induced" OBT is that rapid aileron roll must often be stopped with the opposite aileron deployment (Lohmann, 2003), giving the impression that this is due to OBT. In the case of weak lateral (spiral) stability (convergence), even small aileron misrig- 
ging and misalignments can induce noticeable rolling moments, which again may be interpreted as OBT. Flight control friction, cable tension, loose pushrods, and other problems in reversible flight control systems may lead to an impression that OBT exists. To make things even more complicated, one needs to consider all propulsive moments. A clockwise turning propeller will cause the opposing torque and the left roll, which may become important in high-power left steep-turns, giving an impression of OBT. Some likely causes of apparent OBT can be summarized:

1. Spiral divergence (weak and slow spiral instability) inherent in many (often older) fixed-wing aircraft designs.

2. The above spiral divergence phenomenon supported in steep turns in aircraft with low wing loading (low stalling speed) and tight radii of turn.

3. Propeller slipstream effects (only SE airplanes) on upper (raised) wing in sideslip from the lowered wing side. ME airplanes may experience OBT if the propeller thrust on the upper wing is higher than on the lower wing.

4. Possible nonlinear effects caused by coupled highrate rolling, yawing, and pitching.

5. Possible inertial coupling at high rotations.

6. Gyroscopic (turning propellers) effects.

7. Flight at very high AOA where dihedral effect (roll stiffness) and roll damping are significantly reduced (spin entry).

8. Inertia of rolling (banking motion) and constant changes of bank angle (pilot-induced OBT).

9. Airplane rigging and flight control system friction and misalignments.

10. Subjective human behavior interpreting overbanking in steep turns for any reason as threatening while UBT is disregarded as non-threatening and annoying.

The most likely explanation of what is referred to as OBT is thus based on the stick-fixed aircraft spiral divergence supported by the wing speed differential effect in steep turns. As the sideslip will invariably develop in turns, the effective dihedral effect $C_{l_{\beta}}<0$ will attempt to roll the aircraft away from it. Simultaneously, the directional static stability term $C_{n_{\beta}}>0$ will seek to remove sideslip aligning aircraft's longitudinal axis with the relative wind. As the airplane initially rolls away from sideslip due to lateral stiffness and yaws into it due to yaw stiffness, the dynamic cross-derivative $C_{l_{r}}>0$ induces roll opposite of dihedral effect (roll into sideslip). As the yawing rotation starts the yaw (dynamic stability), the damping term $C_{n_{r}}<0$ opposes yawing motion in a way similar to roll damping opposing roll motion. To make things more complicated (or interesting), the conjugate of the roll-due-to-yaw $C_{l_{r}}>0$ is now yaw-due-to-roll dynamic stability cross-derivative $C_{n_{p}}<0$, which is typically negative for FAR 23 airplanes, and which now yaws the airplane away from the roll direction in support of dihedral effect. Yaw-due-to-roll is a phenomenon that many pilots have truly mastered, and it is commonly called "adverse yaw". If yaw damping and negative yaw-due-to-roll is powerful enough, then it will slow down roll-due-to-yaw, reduce speed, and lift differential as well as the induced roll moment opposing dihedral, reducing the bank angle. The question is thus if the combined effect of dihedral, negative yaw-due-to-roll, and yaw damping will overpower yaw stiffness, roll damping, and roll-due-to-yaw. It is the relative magnitude of these different static and dynamic stability derivatives that define which prevails. Generally, if directional characteristics overpower lateral characteristics, an airplane will continuously yaw and roll into a sideslip resembling the OBT phenomenon. If the lateral characteristics overpower directional, an airplane will ultimately roll away from sideslip. Due to longitudinal coupling and stability, an airplane experiencing spiral divergence will start losing altitude and speed up in ever tightening spiral. It is almost impossible to explain spiral stability in simpler terms. This explanation is similar to how the great genius of flying, Wolfgang Langewiesche (1972), described OBT, which apparently was later lost in translation. This probably also explains why the engineering stability, control community, and aircraft designers never acknowledged or appreciated anything called OBT.

There are arguments made that dihedral effect cannot provide any resistance to roll if the turn is made perfectly coordinated. However, that is impossible as the airplane is straight (almost rigid) and relatively long (finite size) and is not a mathematical point. An airplane cannot follow the curvature of the turn perfectly. It cannot flex and bend itself to meet an arbitrary curvature of the turning flow, and there will always be freestream sideslip (a sort of directional AOA) in turns.

Based on flight conditions such as altitude and airspeed, the stability derivatives can change and an airplane may show totally different behavior. For example, an airplane with an acceptable D-R mode at lower altitude may become outright dangerous at high altitudes (and high M-numbers and AOAs). Additionally, flight at high AOA presents a real problem, and the ultimate limit of the smalldisturbance flight dynamics theory. Chambers and Anglin (1969) show how the roll stiffness becomes positive (unstable) around stalling AOAs for the case of a twinengine fighter jet. Similarly, directional stiffness is lost, resulting in severe heading divergence converging spiral mode with the occurrence of unstable D-R oscillatory mode. Additionally, low Reynolds numbers (corresponding to high altitudes) reduce longitudinal stability in connection with the leading-edge droop utilized to reduce aforementioned heading divergence. At stalling angle, the lateral stability (dihedral effect) and positive roll damping are lost entirely, and it is the raison d'etre for spin origin. Indeed, OBT becomes stronger as airspeed decreases and where the 
aileron control authority is weaker, requiring larger control deflections to arrest unwanted roll.

\section{Conclusions}

Differential lift generated in constant-altitude, constantairspeed turning flight will generate a rolling moment toward the inside of the turn, giving credence to what is called OBT. A generalized yet simple theory of differential lift in horizontal turns was developed here. Uniform lift distribution has been assumed over two wing halves resulting in lift acting at midpoint of each half-span. It has been shown that the largest rolling moment is generated exactly at $45^{\circ}$ bank angle for constant airspeed turns. If the constant stall margin is maintained throughout the steep turn, then the maximum rolling moment will be generated closer to $55^{\circ}$ bank angle. However, it is not clear if this turning induced lift-differential is already included in rollstiffness and/or other stability derivatives. The linear stability theory does not give any space to the notion that rolling moment will depend on the bank angle. It is thus most likely that apparent OBT is simply a consequence of the weakly stable or unstable spiral-mode L-D stability which leads to interplay of sideslip, yaw, and roll into ever tightening high-speed downward spiral combined with the lift differential from a banked wing and accelerated flight. Nevertheless, gentle spiral divergence with large times to double amplitudes is intentionally designed in many airplanes while simultaneously minimizing annoying D-R mode. Several other factors that may contribute to apparent OBT are also discussed. Aggressive rolling into steep-turn often must be arrested by opposite aileron. Rigging problems, friction and misalignment of flight controls may also lead to apparent OBT. A human pilot will always interpret OBT as a bigger threat than any UBT. However, steep turns at very high AOAs may have more pronounced OBT due to changes in stability derivatives close to critical AOAs. If propeller slipstream in turning sideslips indeed induces OBT, that argument alone then does not support OBT origin in unpowered gliders.

\section{References}

Abzug, M. J., \& Larrabee, E. E. (1997). Airplane stability and control: A history of the technologies that made aviation possible. Cambridge, UK: Cambridge University Press.

Anderson, D. F., \& Eberhardt, S. (2001). Understanding flight. New York, NY: McGraw-Hill.

Anderson, J. D., Jr. (1999). Aircraft performance and design. New York, NY: McGraw-Hill.

Ashley, H. (1992). Engineering analysis of flight vehicles. Mineola, NY: Dover.

Askue, V. (2006). Flight testing of homebuilt aircraft. Newcastle, WA: Aviation Supplies and Academic.

Asselin, M. (1997). An introduction to aircraft performance. Reston, VA: American Institute for Aeronautics and Astronautics.

Biber, K. (2006). Stability and control characteristics of a new FAR 23 airplane. Journal of Aircraft, 43(5), 1361-1368.
Campbell, R. D., \& Tempest, B. (1989). Basic aerobatics. Shrewsbury, UK: Airlife Publishing Ltd.

Chambers, J. R., \& Anglin, E. L. (1969). Analysis of lateral-directional stability characteristics of a twin-jet fighter airplane at high angles of attack (NASA TN D-5361). Washington, DC: NASA.

Conway, C. (1989). The joy or soaring. Hobbs, NM: Soaring Society of America.

Cooper, G. E., \& Harper, R. P., Jr. (1969). The use of pilot rating in the evaluation of aircraft handling qualities (NASA TN D-5153). Washington, DC: NASA.

Cram, J. R., \& Brimm, D. J., Jr. (1940). Civil pilot training manual. Civil Aeronautics Bulletin No. 23. Washington, DC: United States Government Printing Office.

Denker, J. S. (2001). See how it flies. Retrieved from www.av8n.com/how/

Eshelby, M. E. (2000). Aircraft performance: Theory and practice. Boston, MA: Elsevier.

Etkin, B. (1959). Dynamics of flight: Stability and control. New York, NY: John Wiley \& Sons.

Etkin, B. (2005). Dynamics of atmospheric flight. Mineola, NY: Dover.

Federal Aviation Administration. (2002a). Private pilot; Practical test standards for airplane (SEL, MEL, SES, MES) (PTS FAA-S-808114A). Washington, DC: Author.

Federal Aviation Administration. (2002b). Commercial pilot; Practical test standards for airplane (SEL, MEL, SES, MES) (PTS FAA-S-808114B). Washington, DC: Author.

Federal Aviation Administration. (2004). Airplane flying handbook (Advisory Circular FAA-H-8083-3A). Washington, DC: Author.

Federal Aviation Administration. (2011). Flight test guide for certification of Part 23 airplanes (Advisory Circular AC 23-8C). Washington, DC: Author.

Federal Aviation Administration. (2013a). Glider flying handbook (Advisory Circular FAA-H-8083-13A). Washington, DC: Author.

Federal Aviation Administration. (2013b). Part 23, Airworthiness Standards: Normal utility and aerobatic airplanes. Washington, DC: Author.

Field, E. J., Rossitto, K. F., \& Hodgkinson, J. (2004). Flying qualities applications of frequency responses identified from flight data. Journal of Aircraft, 41(4), 711.

Garrison, P. (2011, November). Is there an overbanking tendency? Flying, 138(11), 70.

Grenestedt, J. L., \& Maroun, W. (2006). Flight testing a simple fix to lateral stability deficiencies. Journal of Aircraft, 43(5), 1399.

Hale, F. J. (1984). Introduction to aircraft performance, selection, and design. New York, NY: John Wiley \& Sons.

Hodgkinson, J. (1999). Aircraft handling qualities. Reston, VA: American Institute for Aeronautics and Astronautics (AIAA).

Hubin, W. N. (1992). The science of flight: Pilot-oriented aerodynamics. Ames, IA: Iowa State University Press.

Hurt, H. H., Jr. (1965). Aerodynamics for naval aviators. Renton, WA: Aviation Supplies and Academic.

Kershner, W. K. (1994). The advanced pilot's flight manual. Ames, IA: Iowa State University Press.

Kershner, W. K. (1996). The basic aerobatic manual. Ames, IA: Iowa State University Press.

Kimberlin, R. D. (2003). Flight testing of fixed-wing aircraft. Reston, VA: American Institute for Aeronautics and Astronautics (AIAA).

Kolk, R. W. (1961). Modern flight dynamics. Englewood Cliffs, NJ: Prentice-Hall.

Langewiesche, W. (1972). Stick and rudder: An explanation of the art of flying. New York, NY: McGraw-Hill.

Lohmann, D. (2003, May). Lift or speed: Questioning the overbanking tendency. Mentor, 5(5), 12-13.

Mair, W. A., \& Birdsall, D. L. (1992). Aircraft performance. Cambridge, UK: Cambridge University Press.

Mason, S. (1982). Stalls, spins, and safety. New York, NY: McGraw-Hill. 
McCormick, B. W. (1995). Aerodynamics, aeronautics and flight mechanics (2nd ed.). New York, NY: John Wiley \& Sons.

Nelson, R. C. (1998). Flight stability and automatic control (2nd ed.). New York, NY: McGraw-Hill.

Nicolai, L. M., \& Carichner, G. E. (2010). Fundamentals of aircraft and airship design: Volume I-Aircraft design. Reston, VA: American Institute for Aeronautics and Astronautics (AIAA).

Perkins, C. D. (1969). The development of airplane stability and control technology. 1969 von Karman lecture, AIAA Paper No. 69-1137, American Institute for Aeronautics and Astronautics (AIAA) 6th Annual Meeting and Technical Display, Anaheim, CA, October, 2024, 1969.

Phillips, W. F. (2004). Mechanics of flight. New York, NY: John Wiley \& Sons, Inc.

Piggott, D. (2002). Gliding: A handbook on soaring flight (8th ed.). London, UK: A \& C Black Publishers Ltd.

Raymer, D., P. (1999). Aircraft design: A conceptual approach (3rd ed.). Reston, VA: American Institute for Aeronautics and Astronautics (AIAA).

Roskam, J. (2007). Airplane flight dynamics and automatic flight controls. Part I, Lawrence, KS: DAR Corporation.
Russell, J. B. (1996). Performance and stability of aircraft. London, UK: Arnold \& Porter LLP.

Saarlas, M. (2007). Aircraft performance. Hoboken, NJ: John Wiley \& Sons.

Schmidt, D. K. (2012). Modern fight dynamics. New York, NY: McGrawHill.

Seckel, E. (1964). Stability and control of airplanes and helicopters. New York, NY: Academic Press.

Smith, H. C. (1992). The illustrated guide to aerodynamics (2nd ed.). New York, NY: McGraw-Hill.

Stengl, R. F. (2004). Flight dynamics. Princeton, NJ: Princeton University Press.

Stevens, B. L., \& Lewis, F. L. (2003). Aircraft control and simulation (2nd ed.). Hoboken, NJ: John Wiley \& Sons.

Stewart, K. (2001). The glider pilot's manual (3rd ed.). Shrewsbury, UK: Airlife Publishing Ltd.

Swatton, P. J. (2008). Aircraft performance: Theory and practice for pilots (2nd ed.). Chichester, UK: John Wiley \& Sons.

Swatton, P. J. (2011). Principles of flight for pilots. Chichester, UK: John Wiley \& Sons.

Vinh, N. X. (1993). Flight mechanics of high-performance aircraft. Cambridge, UK: Cambridge University Press. 